\title{
Conformational and Coordination Equilibria on DOTA Complexes of Lanthanide Metal Ions in Aqueous Solution Studied by ${ }^{1} \mathrm{H}-\mathrm{NMR}$ Spectroscopy
}

\author{
Silvio Aime, ${ }^{*}, \dagger$ Mauro Botta,${ }^{\dagger}$ Mauro Fasano, ${ }^{\dagger}$ M. Paula M. Marques, ${ }^{\ddagger}$ \\ Carlos F. G. C. Geraldes, ${ }^{*}$, Dirk Pubanz, ${ }^{\S}$ and André E. Merbach ${ }^{*, \S}$
}

Dipartimento di Chimica Inorganica, Chimica Fisica e Chimica dei Materiali dell'Università degli Studi di Torino, Via P. Giuria, 7, 10127 Torino, Italy, Institut de Chimie Minérale et Analytique, Université de Lausanne, BCH, 1015 Lausanne, Switzerland, and Departamento de Bioquímica, Faculdade de Ciências e Tecnologia da Universidade de Coimbra, Apartado 3126, 3000 Coimbra, Portugal

Received November 14, $1996^{\otimes}$

\begin{abstract}
A variable-temperature, -pressure, and -ionic strength ${ }^{1} \mathrm{H}$ NMR study of the DOTA complexes of different trivalent cations ( $\mathrm{Sc}, \mathrm{Y}, \mathrm{La}, \mathrm{Ce} \rightarrow \mathrm{Lu}$ ) (DOTA = 1,4,7,10-tetraaza-1,4,7,10-tetrakis(carboxymethyl)cyclododecane) yielded data that are in contradiction with the hitherto used model of only two enantiomeric pairs of diastereoisomers that differ in the ligand conformations. A two-isomer equilibrium cannot explain the newly observed apparent reversal of the isomer ratio at the end of the series. As both conformers may lose their inner sphere water molecule, a coordination equilibrium may be superimposed on this conformational equilibrium, as shown by large positive reaction volumes for the isomerization of $\left[\mathrm{Ln}(\mathrm{DOTA})\left(\mathrm{H}_{2} \mathrm{O}\right)_{x}\right]^{-}(\mathrm{Ln}=\mathrm{Yb}, \mathrm{Lu} ; x=1,0)$. The isomerization of $\left[\mathrm{Nd}(\mathrm{DOTA})\left(\mathrm{H}_{2} \mathrm{O}\right)\right]^{-}$and $\left[\mathrm{Eu}(\mathrm{DOTA})\left(\mathrm{H}_{2} \mathrm{O}\right)\right]^{-}$is purely conformational, as shown by near-zero reaction volumes. The measured isomerization enthalpies and entropies agree with this model. The shift of the isomerization equilibria by a variety of non-coordinative salts depends on the ligand conformation rather than the presence or absence of the inner sphere water molecule. This results from weak ion binding and water solvent stabilization of one ligand conformation, rather than the decrease of the activity of the bulk water in the solution, as shown by UVvis measurements of the coordination number sensitive transition ${ }^{5} \mathrm{~F}_{0} \rightarrow{ }^{7} \mathrm{D}_{0}$ of $\mathrm{Eu}(\mathrm{III})$ as a function of ionic strength. Fluoride ions replace a water molecule in the inner coordination sphere, preferentially for one of the conformational isomers, as proven by ${ }^{19} \mathrm{~F}-\mathrm{NMR}$ shifts and the appearance of a third set of resonances corresponding to $[\mathrm{Eu}(\mathrm{DOTA}) \mathrm{F}]^{2-}$ in the ${ }^{1} \mathrm{H}-\mathrm{NMR}$ spectrum of $\left[\mathrm{Eu}(\mathrm{DOTA})\left(\mathrm{H}_{2} \mathrm{O}\right)\right]^{-}$.
\end{abstract}

\section{Introduction}

The high thermodynamic stability, conformational rigidity, and kinetic inertia shown by $\mathrm{Ln}^{\mathrm{III}}$ (DOTA) (DOTA $=1,4,7,10$ tetraaza-1,4,7,10-tetrakis(carboxymethyl)cyclododecane) complexes are the result of a very good match between sizes of Ln(III) ions and the preformed cavity of the DOTA ligand. ${ }^{1}$ From the reported X-ray solid-state structures of $\mathrm{Ln}^{\mathrm{III}}$ (DOTA) complexes $\left(\mathrm{Ln}=\mathrm{Eu},{ }^{2} \mathrm{Gd},{ }^{3} \mathrm{Lu}^{4}\right)$, it is known that the ligand provides eight coordination sites (four nitrogens and four oxygens) arranged in a square-antiprismatic geometry around the lanthanide ion. A ninth coordination site, at a capping position above the plane of the four oxygens, is occupied by one water molecule. In solution this water molecule is exchanging rapidly with the bulk solvent, and, in the case of Gd(DOTA $)^{-5}$ it results in an overall, remarkable increase in the relaxation rate of the solvent water protons. These two properties have been of primary importance in promoting the

* To whom correspondence should be addressed.

$\dagger$ Università degli Studi di Torino.

¥ Universidade de Coimbra.

$\S$ Université de Lausanne.

${ }^{\otimes}$ Abstract published in Advance ACS Abstracts, April 1, 1997.

(1) Desreux, J. F. Inorg. Chem. 1980, 19, 1319.

(2) Spirlet, M. R.; Rebizant, J.; Desreux, J. F.; Loncin, M. F. Inorg. Chem. 1984, 23, 359

(3) (a) Dubost, J.-P.; Leger, M.; Langlois, M.-H.; Meyer, D.; Schaefer, M. C. R. Acad. Sci., Ser. 2 1991, 312, 349. (b) Chang, C. A.; Francesconi, I. C.; Malley, M. F.; Kumar, K.; Gougoutas, J. Z.; Tweedle, M. F.; Lee, D. W.; Wilson, L. J. Inorg. Chem. 1993, 32, 3501 .

(4) Aime, S.; Barge, A.; Botta, M.; Fasano, M.; Ayala, J. D.; Bombieri, G. Inorg. Chim. Acta 1996, 246, 423.

(5) Koenig, S. H.; Brown, R. D., III Prog. Nucl. Magn. Reson. Spectrosc. 1991, 22, 487. use of $\mathrm{Gd}(\mathrm{DOTA})^{-}$as a contrast agent for magnetic resonance imaging applications. ${ }^{6}$

The square-antiprismatic geometry of $\operatorname{Ln}(\text { DOTA })^{-}$complexes implies the occurrence of two helicities (one belonging to the cycle and one associated with the layout of the acetate arms) which may give rise to two enantiomeric pairs of diastereoisomers. ${ }^{7}$ Figure 1 shows a schematic representation of the structure and dynamics of the diastereoisomers of the $\operatorname{Ln}(\text { DOTA })^{-}$ complexes. Two isomers are actually observed in solution in the ${ }^{1} \mathrm{H}$ - and ${ }^{13} \mathrm{C}$-NMR spectra of all $\mathrm{Ln}(\mathrm{DOTA})^{-}$complexes in slow exchange at room temperature, one with larger shifts (due to larger anisotropic susceptibility) than the other. Their structures were determined from the analysis of the dipolar shifts in the ${ }^{1} \mathrm{H}-\mathrm{NMR}$ spectrum of $\mathrm{Yb}(\mathrm{DOTA})^{-} .{ }^{8}$ Because of their relative concentrations in the $\mathrm{Yb}(\mathrm{DOTA})^{-}$solutions, as shown by the relative intensities of the corresponding resonances in the ${ }^{1} \mathrm{H}-\mathrm{NMR}$ spectrum, these isomers were called $\mathrm{M}$ (major) and $\mathrm{m}$ (minor). ${ }^{8}$ The structure found for the $\mathrm{M}$ isomer ${ }^{8}$ closely resembles those observed in the $\mathrm{X}$-ray diffraction studies of $\mathrm{Eu},{ }^{2}$ $\mathrm{Gd}^{3 \mathrm{a}}{ }^{\mathrm{Y}},^{3 \mathrm{~b}}$ and $\mathrm{Lu}(\mathrm{DOTA})^{-4}$ complexes, displaying a regular antiprismatic geometry of the DOTA ligand around the lanthanide ion. Conversely, a less regular coordination geometry has been found for the $\mathrm{m}$ isomer, whose structure may be envisaged as an inverted antiprism, strongly distorted toward a regular prism. ${ }^{8}$ Thus, on going from the $\mathrm{M}$ to the $\mathrm{m}$ structure the $\mathrm{O}_{4}$ square rotates around the symmetry axis, changing both the sign and the magnitude of the antiprism tilt angle. This

(6) Kumar, K.; Tweedle, M. F. Pure Appl. Chem. 1993, 65, 515.

(7) (a) Corey, E. J.; Bailar, J. C., Jr. J. Am. Chem. Soc. 1959, 81, 2620. (b) Beattie, J. K. Acc. Chem. Res. 1971, 4, 253.

(8) Aime, S.; Botta, M.; Ermondi, G. Inorg. Chem. 1992, 31, 4291. 

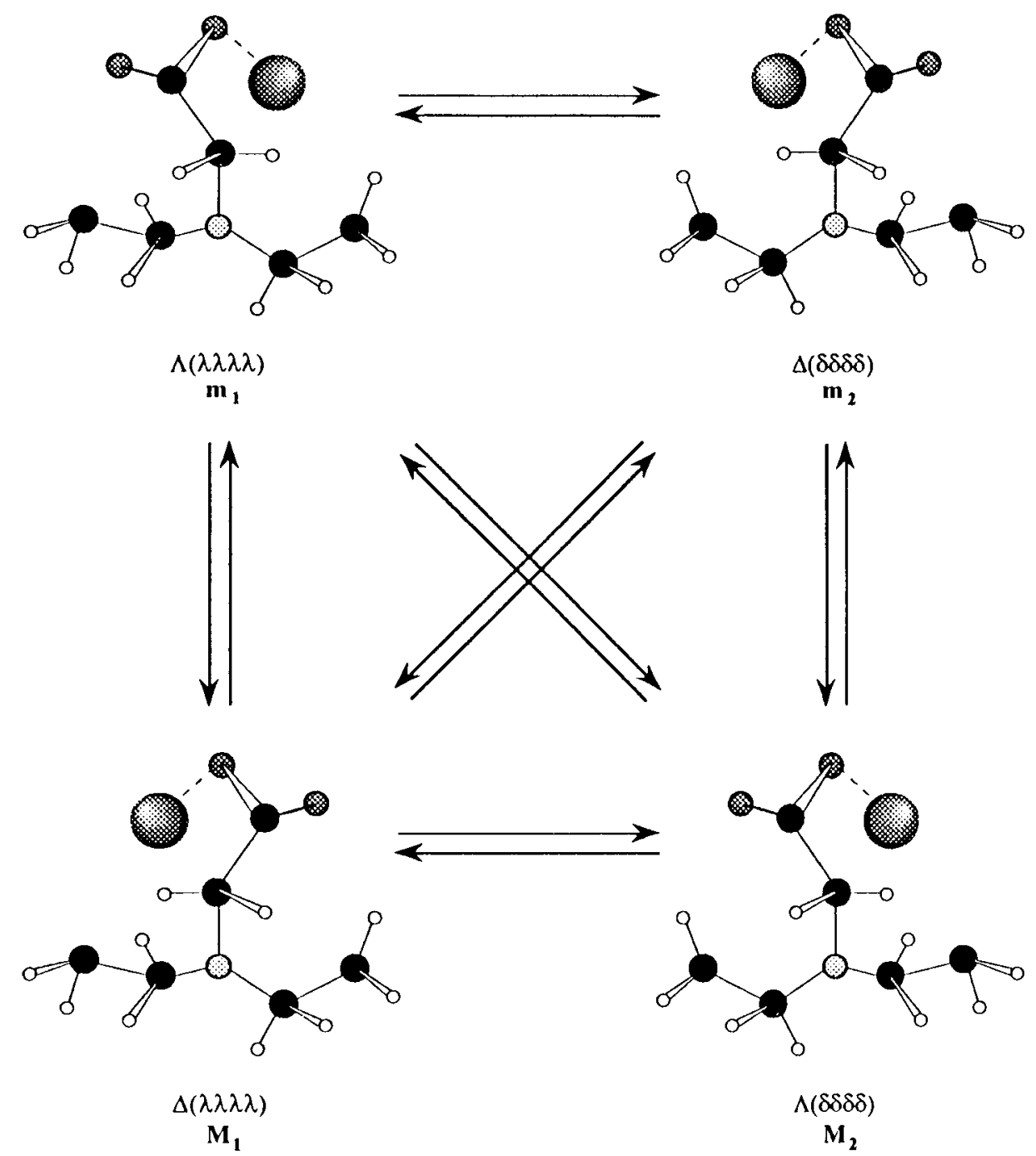

Figure 1. Schematic representation of the structure and dynamics of the diastereoisomers of the $\operatorname{Ln}(\mathrm{DOTA})^{-}$complexes. Only the geometry around one of the bound $\mathrm{N}-\mathrm{CH}_{2}-\mathrm{COO}$ groups is given. The isomer denominations are according to IUPAC rules. ${ }^{7}$ The symbols $\Lambda$ and $\Delta$ refer to the helicity of the acetate arms, and $\lambda \lambda \lambda \lambda$ and $\delta \delta \delta \delta$, to the cycle. Here the conformational process is shown for the $\mathrm{M}$ and $\mathrm{m}$ forms but is equally applicable to $\mathrm{M}^{\prime}$ and $\mathrm{m}^{\prime} . \mathrm{M}_{1}$ and $\mathrm{M}_{2}$, as well as $\mathrm{m}_{1}$ and $\mathrm{m}_{2}$, named in agreement with the literature, ${ }^{19,24}$ are NMR indistinguishable enantiomeric pairs respectively for the $\mathrm{M}$ and $\mathrm{m}$ forms detected by NMR.

m-type structure may be recognized in several X-ray solid-state structures of other macrocyclic complexes such as La(DOTAM) $($ DOTAM $=1,4,7,10$-tetrakis(2-carbamoylethyl)-1,4,7,10-tetraazacyclododecane), ${ }^{9} \mathrm{Eu}(\mathrm{THP})(\mathrm{THP}=1,4,7,10$-tetrakis $(2$ hydroxypropyl)-1,4,7,10-tetraazacyclododecane), ${ }^{10} \mathrm{Y}\left(\mathrm{DOTPBz}_{4}\right)$ $($ DOTPBz $4=1,4,7,10$-tetraazacyclododecane tetrakis(methylenebenzylphosphinic acid)), ${ }^{11}$ and Gd(DO3MA) (DO3MA = $(1 R, 4 R, 7 R)-\alpha, \alpha^{\prime}, \alpha^{\prime \prime}$-trimethyl-1,4,7,10-tetraazacyclododecane1,4,7-triacetic acid). ${ }^{12}$ An analogous structure made up of eight nitrogens has been reported for the sodium salt of a pyrazolefunctionalized tetraazamacrocycle $\mathrm{Mn}$ (II) complex. ${ }^{13,14}$

Inspection of the ${ }^{1} \mathrm{H}$ - and ${ }^{13} \mathrm{C}-\mathrm{NMR}$ spectra along the lanthanide series suggested that an inversion in $\mathrm{M}$ and $\mathrm{m}$

(9) Morrow, J. R.; Amin, S.; Lake, C. H.; Churchill, M. R. Inorg. Chem. $1993,32,4566$.

(10) Chin, K. O. A.; Morrow, J. R.; Lake, C. H.; Churchill, M. R. Inorg. Chem. 1994, 33, 656.

(11) Aime, S.; Batsanov, A. S.; Botta, M.; Howard, J. A. K.; Parker, D.; Senanayake, K.; Williams, G. Inorg. Chem. 1994, 33, 4696.

(12) Kang, S. I.; Ranganathan, R. S.; Emswiler, J. E.; Kumar, K.; Gougoutas, J. Z.; Malley, M. F.; Tweedle, M. F. Inorg. Chem. 1993, 32, 2912.

(13) de Martino Norante, G.; Di Vaira, M.; Mani, F.; Mazzi, S.; Stoppioni, P. J. Chem. Soc., Chem. Commun. 1990, 438.

(14) Di Vaira, M.; Mani, F.; Stoppioni, P. J. Chem. Soc., Dalton Trans. $1992,1127$. populations occurs between La- and Lu(DOTA) ${ }^{-8}$ (see also Figure 3). The determinations of the X-ray structures of La- ${ }^{15}$ and Lu(DOTA $)^{-4}$ confirm this suggestion, showing an m-type structure for the former and an M-type for the latter. It appears then reasonable to assign the major set of resonances in the spectra of $\mathrm{La}(\mathrm{DOTA})^{-}$to the $\mathrm{m}$ isomer and that one of $\mathrm{Lu}$ (DOTA) ${ }^{-}$to the $\mathrm{M}$ isomer. However, in an effort to more thoroughly characterize the isomer equilibrium for the Ln(DOTA $)^{-}$complexes along the lanthanide series in its structural and thermodynamic aspects, we report in this publication a systematic ${ }^{1} \mathrm{H}-\mathrm{NMR}$ study of the effects of temperature, pressure, and ionic strength of the aqueous solution upon that speciation equilibrium for the whole lanthanide series. We show that a simple two-isomer equilibrium does not satisfy the experimental facts. We propose the model shown in Figure 2, where a coordination equilibrium is superimposed on the conformational equilibrium of Figure 1 . The change of coordination number is due to the loss of the inner sphere water molecule (left/right), and the diastereomeric pairs which originate the different anisotropic susceptibilities are represented by the sign and magnitude of the tilt angle of the antiprism (top/

(15) Bombieri, G. Abstract, COST Working Group Meeting on "Synthesis and Physicochemical Studies of Lanthanide and Transition Metal Chelates of Relevance to MRI", Torino, Italy, 1994. 




Figure 2. Conformational and coordination equilibria proposed in this work for the $\left[\operatorname{Ln}(\text { DOTA })\left(\mathrm{H}_{2} \mathrm{O}\right)_{x}\right]^{-}$complexes in aqueous solution. Enantiomeric pairs are not represented.

bottom). Thus, the majuscule $\mathrm{M}$ and $\mathrm{M}^{\prime}$ assign the $\Delta(\lambda \lambda \lambda \lambda) /$ $\Lambda(\delta \delta \delta \delta)$ pair, with $(\mathrm{M})$ and without $\left(\mathrm{M}^{\prime}\right)$ inner sphere water, and the minuscule $\mathrm{m}$ and $\mathrm{m}^{\prime}$ the $\Lambda(\delta \delta \delta \delta) / \Delta(\lambda \lambda \lambda \lambda)$ pair, with $(\mathrm{m})$ and without $\left(\mathrm{m}^{\prime}\right)$ inner sphere water. The transformations between $M$ and $M^{\prime}$, or between $m$ and $m^{\prime}$, species, which differ in the coordination of one water molecule, appear to be fast on the proton NMR time scale and thus not distinguishable by this technique, as the dissociation and association processes have rate constants in the range of $10^{5}$ to $10^{8} \mathrm{~s}^{-1}$, as shown by ${ }^{17} \mathrm{O}$ NMR. ${ }^{16}$ The other two equilibria, between $\mathrm{M}$ and $\mathrm{m}$ or $\mathrm{M}^{\prime}$ and $\mathrm{m}^{\prime}$, are conformational rearrangements, processes which are slow on the NMR time scale, and lead to different proton spectra. Note that the equilibrium between two enantiomeric pairs of diastereoisomers described by Figure 1 applies to the two conformational equilibria described above (between $\mathrm{M}$ and $\mathrm{m}$, as well as betwen $\mathrm{M}^{\prime}$ and $\left.\mathrm{m}^{\prime}\right)$. We will show in this work that this model is capable of explaining the whole set of NMR data.

\section{Experimental Section}

The DOTA ligand was synthesized according to the published procedure. ${ }^{1}$ All the $\operatorname{Ln}(\text { DOTA })^{-}$complexes were prepared as sodium salts in aqueous solution by reacting stoichiometric amounts of the acid form of the ligand, the lanthanide(III) oxide (Aldrich Chemical Co), and $\mathrm{NaOH}$. In a typical reaction the appropriate $\mathrm{Ln}_{2} \mathrm{O}_{3}(1.0 \mathrm{mmol})$, $\mathrm{H}_{4}$ DOTA ( $\left.810 \mathrm{mg} ; 2.0 \mathrm{mmol}\right)$, and $2 \mathrm{~N} \mathrm{NaOH}(1 \mathrm{~mL} ; 2.0 \mathrm{mmol})$ were mixed in $24 \mathrm{~mL}$ of deionized water. The white suspension was heated at $80{ }^{\circ} \mathrm{C}$ under magnetic stirring until a clear solution was obtained. After cooling to room temperature, the reaction mixture was filtered and centrifuged and the resulting solution evaporated in vacuo to give the solid complex (yield $\geq 90 \%$ ).

Solutions for ${ }^{1} \mathrm{H}$-NMR spectroscopy have been prepared by dissolving the solid complex in $\mathrm{D}_{2} \mathrm{O}$. Chemical shifts have been referenced with respect to tert-butyl alcohol as an internal standard. The $\mathrm{pH}$ of the solutions was adjusted with $\mathrm{DCl}$ and $\mathrm{CO}_{2}$-free $\mathrm{NaOD} .{ }^{1} \mathrm{H}-\mathrm{NMR}$ spectra were recorded on JEOL EX-90 (at $2.1 \mathrm{~T}$ ) and JEOL EX-400 (at 9.4 T) spectrometers (Torino), Bruker AC 200 (at $4.7 \mathrm{~T}$ ) and Bruker ARX 400 (at $9.4 \mathrm{~T}$ ) spectrometers (Lausanne), and a Varian Unity 500 (at $11.8 \mathrm{~T}$ ) spectrometer (Coimbra), whereas ${ }^{19} \mathrm{~F}-\mathrm{NMR}$ spectra were recorded at $84.7 \mathrm{MHz}$ on a JEOL EX-90 spectrometer. UV-vis spectra were obtained on a double beam Perkin-Elmer lambda 19 spectrophotometer, connected to an IBM compatible PC using the program PECSS 4.01 to record the spectra. ${ }^{16 \mathrm{~d}}$

Variable-temperature ${ }^{1} \mathrm{H}-\mathrm{NMR}$ spectra were used to obtain the isomer equilibrium constants. These were calculated from peak areas (integration) of the more shifted (downfield or upfield) peaks of each isomer following the scheme $K_{1}=[\mathrm{M}] /[\mathrm{m}]$ (from La(III) to Ho(III) complexes) and $K_{2}=\left[\mathrm{m}^{\prime}\right] /[\mathrm{M}]$ (from $\operatorname{Er}(\mathrm{III})$ to $\mathrm{Lu}(\mathrm{III})$ complexes). Temperature

(16) (a) Micskei, K.; Helm, L.; Brücher, E.; Merbach, A. E. Inorg. Chem. 1993, 32, 3844. (b) González, G.; Powell, D. H.; Tissières, V.; Merbach, A. E. J. Phys. Chem. 1994, 98, 53. (c) Pubanz, D.; González, G.; Powell, D. H.; Merbach, A. E. Inorg. Chem. 1995, 34, 4447. (d) Graeppi, N.; Powell, D. H., Laurenczy, G.; Zékány, L.; Merbach, A. E. Inorg. Chim. Acta 1995, 235, 311. dependence studies of the isomer equilibria were carried out at 400 $\mathrm{MHz}$ in temperature ranges which did not affect the slow exchange regime of the ${ }^{1} \mathrm{H}-\mathrm{NMR}$ spectra. The temperature ranges (K) for every lanthanide complex were 274-285 (Pr), 271-301 (Nd), 273-305 (Eu), 275-315 (Ho), 274-308 (Tm), 279-304 (Yb), and 271-284 (Lu). Temperature was calibrated against methanol as internal standard. The errors of the temperature measurements were $\pm 0.2 \mathrm{~K} . \ln \left(K_{i}\right)$ values were plotted against $1 / T$ (van't Hoff plots) according to the equation $\ln \left(K_{i}\right)=-\left(\Delta H^{\circ} / R\right)(1 / T)+\left(\Delta S^{\circ} / R\right)$, and $\Delta H^{\circ}$ and $\Delta S^{\circ}$ were calculated by linear regression analysis of those plots.

Variable-pressure ${ }^{1} \mathrm{H}$-NMR measurements were recorded at $4.7 \mathrm{~T}$ $(200 \mathrm{MHz})$ and $9.4 \mathrm{~T}(400 \mathrm{MHz})$ on the Bruker instruments using homebuilt, narrow-bore, high-pressure probe heads. ${ }^{17 \mathrm{a}-\mathrm{c}}$ The temperature was stabilized by circulating a thermostatic fluid and controlled with a built-in Pt-100 resistor connected to a five-digit electronic thermometer "Tracker 130" from GP Electronic AG, Zürich, Switzerland. The applied pressure was measured with the digital manometer "Eurotherm" from Nova AG, Effretikon, Switzerland. The isomer ratio has been evaluated as described above, by Lorentzian curve fitting after base line correction (WinNMR, Bruker Analytische Messtechnik, Silberstreifen, Rheinstetten, Germany).

Variable-ionic strength ${ }^{1} \mathrm{H}-\mathrm{NMR}$ studies were carried out at $500 \mathrm{MHz}$ with $0.02 \mathrm{M} \operatorname{Ln}\left(\right.$ DOTA) ${ }^{-}$aqueous solutions at $\mathrm{pH} 7.0$ and $293 \mathrm{~K}$, in the absence and presence of increasing concentrations of the salts $\mathrm{LiCl}$, $\mathrm{NaCl}, \mathrm{MgCl}_{2}, \mathrm{NaClO}_{4}, \mathrm{NaBr}$, and $\mathrm{KI}$ (from Aldrich), and at $400 \mathrm{MHz}$ with $0.1 \mathrm{M} \mathrm{Ln}(\mathrm{DOTA})^{-}$aqueous solutions, in the absence and presence of the salt $\mathrm{NaF}$ (from Aldrich). Variable-temperature ${ }^{1} \mathrm{H}-\mathrm{NMR}$ spectra in the presence of high salt concentrations have been carried out at $200 \mathrm{MHz}$ in the temperature range of $269-311 \mathrm{~K}$ on $0.04 \mathrm{M}$ $\mathrm{Eu}(\text { DOTA })^{-}$solutions in $2 \mathrm{M} \mathrm{NaClO}_{4}$ or $2 \mathrm{M} \mathrm{NaCl}$. The temperature was accurately $( \pm 0.5 \mathrm{~K})$ measured by a substitution technique. ${ }^{18}$

\section{Results}

Isomer Ratios Along the Lanthanide Series. Although an estimate of the isomeric ratio of $\operatorname{Ln}(\text { DOTA })^{-}$complexes has already been reported, ${ }^{8,19}$ we have repeated this determination at constant temperature, concentration, and ionic strength. In the case of $\operatorname{Pr}(\text { DOTA })^{-}$and $\mathrm{Lu}(\mathrm{DOTA})^{-}$it was not possible to evaluate the actual isomer ratio by peak integration at $298 \mathrm{~K}$ because the isomers are not in slow exchange on the NMR time scale at this temperature. Thus, in these cases the isomer ratios have been extrapolated from a van't Hoff plot obtained at lower temperatures (see below). In addition to the $\mathrm{Ln}$ (III) complexes, we have considered the diamagnetic Y(DOTA) ${ }^{-}$and Sc(DOTA) ${ }^{-}$ as well. The Y(III) ion has close analogies with lanthanides as it resembles well both the size (ionic radii of 1.019 and 1.075 $\AA$ for coordination numbers of 8 and 9 , respectively) and coordination properties (coordination number 8 or 9) of the Er(III) ion (ionic radii of 1.004 and $1.062 \AA$ for coordination numbers 8 and 9 , respectively). ${ }^{20}$ The smaller Sc(III) ion (ionic radius of $0.870 \AA$ for coordination number 8$),{ }^{20}$ although of somewhat different coordination properties (coordination numbers $6-8$ ), was included in this study in order to provide a wider range of ion size effects on the preferred structures featured by the ligand DOTA in the complexes.

For all the paramagnetic $\operatorname{Ln}(\mathrm{DOTA})^{-}$complexes for which two isomers could be observed by ${ }^{1} \mathrm{H}-\mathrm{NMR}$ spectroscopy, one was found to have larger paramagnetic shifts (larger susceptibility anisotropy) than the other, and for historical reasons ${ }^{8}$

(17) (a) Moullet, B.; Frey, U.; Helm, L.; Tschanz, R.; Ith, R.; Merbach, A. E. High Pressure Res. 1995, 12, 285. (b) Frey, U.; Helm, L.; Merbach, A. E.; Roulet, R. In Advanced Applications of NMR to Organometallic Chemistry; Gielen, M., Willem, R., Wrackmeyer, B., Eds.; Wiley: New York, 1996; Vol. 1, p 193. (c) Cusanelli, A.; Nicula-Dadci, L.; Frey, U.; Merbach, A. E. submitted for publication.

(18) Ammann, C.; Meier, P.; Merbach, A. E. J. Magn. Reson. 1982, 46 , 319.

(19) Hoeft, S.; Roth, K. Chem. Ber. 1993, 126, 869.

(20) Shannon, R. D. Acta Crystallogr. 1976, A32, 751. 


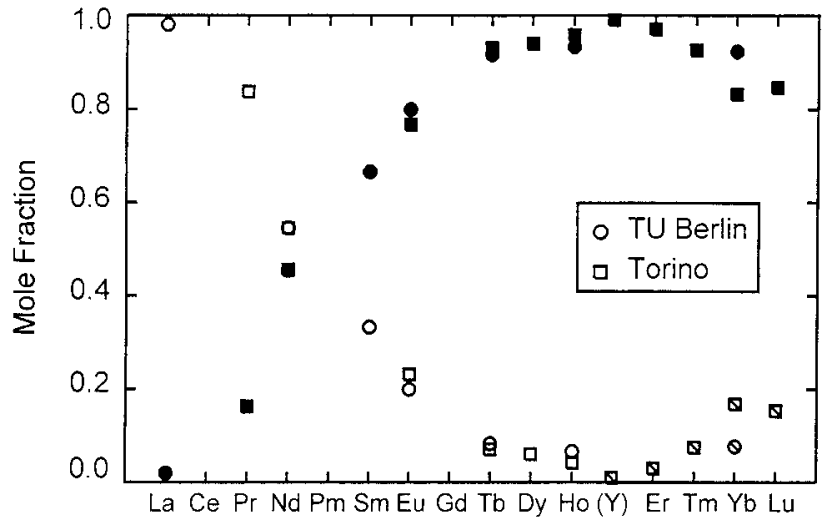

Figure 3. Molar fractions of the isomers $\mathrm{m}$ (open symbols), $\mathrm{m}^{\prime}$ (barred symbols), and $\mathrm{M}$ (filled symbols) of $\left[\mathrm{Ln}(\mathrm{DOTA})\left(\mathrm{H}_{2} \mathrm{O}\right)_{x}\right]^{-}$as a function of the complexed metal ion from ${ }^{1} \mathrm{H}-\mathrm{NMR}$ spectroscopy $(0.15 \mathrm{M}$ Ln(DOTA $)^{-}, \mathrm{pH} 7.0, T=298 \mathrm{~K}$, ionic strength $=0.3 \mathrm{M}$ ): (squares) Aime et al., this work, Torino; (circles) Hoeft and Roth, T. U. Berlin. ${ }^{19}$

described in the Introduction, the first was called $\mathrm{M}$ for major and the second $\mathrm{m}$ for minor. Figure 3 reports the molar fraction of the isomers $\mathrm{M}$ and $\mathrm{m}$ detected by ${ }^{1} \mathrm{H}-\mathrm{NMR}$ spectroscopy along the lanthanide series. Whereas in $\mathrm{Nd}(\mathrm{DOTA})^{-}$the two isomers appear almost equimolar, for the lighter La-, Ce-, and $\operatorname{Pr}(\text { DOTA })^{-}$one isomer (likely the $\mathrm{m}$ isomer) is more abundant. Conversely, for the heavier ions it may be concluded that the main species has the structure of the $\mathrm{M}$ isomer. As opposed to all of the other paramagnetic ions, in which the $\mathrm{M}$ isomer has the larger susceptibility anisotropy, in the Tm(III) chelate the more intense, less shifted proton signals are assigned to the $M$ isomer, ${ }^{8}$ so that the isomer fractions for $\mathrm{Tm}$ (III) fit into the continuous variation from $\mathrm{Er}(\mathrm{III})$ to $\mathrm{Yb}$ (III) (see Figure 3). For the lanthanides heavier than $\mathrm{Ho}(\mathrm{III})$, the mole fraction of $\mathrm{M}$ decreases again with decreasing ionic radius. The sole conformational equilibrium $\mathrm{m} \leftrightarrow \mathrm{M}$ does not provide a physically acceptable explanation for such reversal of the trend of the isomer ratio variation. On the other hand, the observed behavior may be explained by reference to Figure 2, in terms of the formation of a third species. We assume that, among the three structural forms, just two are simultaneously present: the $\mathrm{m}$ isomer dominates at the beginning of the series and is in equilibrium with the $\mathrm{M}$ isomer according to the reaction $\mathrm{m} \leftrightarrow$ M. It decreases its concentration in favor of $M$ as the ionic radius decreases. This leads to the complete disappearance of the $\mathrm{m}$ isomer in the ${ }^{1} \mathrm{H}-\mathrm{NMR}$ spectra of $\operatorname{Er}(\mathrm{DOTA})^{-}$or Y(DOTA $)^{-}$complexes. By further reduction of the size of the $\mathrm{Ln}$ (III) ion, the presence of a third species, $\mathrm{m}^{\prime}$, becomes detectable, in equilibrium with M. According to Figure 2 the new $\mathrm{M} \leftrightarrow \mathrm{m}^{\prime}$ isomer equilibrium involves both depletion of the inner sphere water molecule and a ligand conformational rearrangement. Evidence for the first process will be presented in the variable-pressure section, while the evidence for the slow second process comes from the observation of two species in slow exchange in the ${ }^{1} \mathrm{H}-\mathrm{NMR}$ spectra of all complexes.

The dependence of the isomeric ratio upon the size of the lanthanide ion can be represented in an alternative way by defining the equilibrium constants for the separate steps of the reactions reported in Figure 2 in the order of decreasing cavity size of the ligand $\left(\mathrm{m}>\mathrm{M}>\mathrm{m}^{\prime}>\mathrm{M}^{\prime}\right)$. At the beginning of the series $K_{1}=[\mathrm{M}] /[\mathrm{m}]$, whereas at the end $K_{2}=\left[\mathrm{m}^{\prime}\right] /[\mathrm{M}]$. The values of these isomer ratios at $298 \mathrm{~K}$ are shown in Tables 1 and 2 for the whole lanthanide series. The dependence of these equilibrium constants $K_{i}$ on the ionic radii $r$ was studied through empirical eq 1 , where $A_{i}$ and $C$ are empirical constants,

$$
-R T \ln \left(K_{i}\right)=C / r+A_{i} \quad(i=1-3)
$$

by fitting the experimental $-R T \ln \left(K_{i}\right)$ values to the ionic radii $r$ after Shannon ${ }^{20}$ for coordination number 9 . By using this formalism, we were able to obtain a linear correlation for both transformations, whereas the simple " $\mathrm{M}$ to $\mathrm{m}$ " isomerization would lead to a V-shaped function without any physically sound basis. In fact, a least squares fit of the data to eq 1 yields the top plot in Figure 4 and the values $A_{1}=+135 \pm 9 \mathrm{~kJ} \mathrm{~mol}^{-1}$, $A_{2}=+153 \pm 4 \mathrm{~kJ} \mathrm{~mol}^{-1}$, and $C=-154 \pm 10 \AA^{-1}$.

The $400 \mathrm{MHz}{ }^{1} \mathrm{H}-\mathrm{NMR}$ spectrum of $\mathrm{Sc}(\mathrm{DOTA})^{-}$in $\mathrm{D}_{2} \mathrm{O}$ at $271 \mathrm{~K}$ is quite similar to that reported for $\mathrm{Lu}(\mathrm{DOTA})^{-8},{ }^{8}$ showing the presence of two isomers in slow exchange, with a signal intensity ratio of about 5:1. The multiplicities and chemical shifts of the signals from the most abundant isomer are almost identical to those previously reported ${ }^{8}$ for the major isomer, $\mathrm{M}$, of $\mathrm{Lu}$ (DOTA) ${ }^{-}$, namely, 3.70 (doublet, a) and $3.41 \mathrm{ppm}$ (doublet, c) for the methylenic protons of the acetate groups, 3.46 (triplet, b) and $2.80 \mathrm{ppm}$ (triplet, e) for the axial ethylenic resonances, and 3.41 (doublet, c) and $2.60 \mathrm{ppm}$ (doublet, f) for the equatorial ethylenic signals. Four resonances of the minor isomer can be seen, again like in the $\mathrm{Lu}^{3+}$ complex: 3.95 (a), 3.36 (c), 3.08 (e), and $2.77 \mathrm{ppm}$ (f). Therefore, both the major and minor isomers of $\mathrm{Sc}$ (DOTA) ${ }^{-}$have the ligand in the same conformation as that for $\mathrm{Lu}(\mathrm{DOTA})^{-}$, which exhibits an $\mathrm{M} \leftrightarrow$ $\mathrm{m}^{\prime}$ equilibrium.

The proton spectrum of $\mathrm{Sc}(\mathrm{DOTA})^{-}$remains in slow exchange up to $281 \mathrm{~K}$, but above this temperature exchange broadening occurs. At $296 \mathrm{~K}$, the signals from the minor isomer are too broad to be detected. The isomer ratio calculated for the $\mathrm{Sc}^{3+}$ complex at $298 \mathrm{~K}$ is shown in Table 2 and, when plotted in Figure 4 (top), it is outside both correlations found for the lanthanide complexes. Thus, this observation and the conclusion described above, that the Sc(III) isomers have the same ligand conformation as the corresponding Lu(III) isomers, lead us to propose that for the Sc(DOTA) ${ }^{-}$complex the isomer equilibrium is taking place between two forms without inner sphere water, $\mathrm{m}^{\prime} \leftrightarrow \mathrm{M}^{\prime}$ (see Figure 2). This proposal is supported by pressure dependence studies described later. The corresponding isomer ratio $K_{3}=\left[\mathrm{M}^{\prime}\right] /\left[\mathrm{m}^{\prime}\right]$, when plotted in Figure 4 (top), is the sole representative of this equilibrium. A dotted line parallel to the ones for the $K_{1}$ and $K_{2}$ equilibria, when fitted to eq 1 , gave the value $A_{3}=+173 \mathrm{~kJ} \mathrm{~mol}^{-1}$. It must be pointed out that the linear relation in eq 1 with the same slope for all equilibrium reactions is empirical, it is chosen because it fits the data well. The slope through the Sc data point is arbitrary, but reducing it to half its value does not change the conclusion about the relative stability of the various isomeric species, depicted in Figure 6.

In order to assess the relative stabilities of the species $\mathrm{m}, \mathrm{M}$, and $\mathrm{m}^{\prime}$ and as a control of the consistency of the mechanistic model proposed in Figure 2, it is useful to plot the Gibbs free energy $\Delta G_{0}{ }^{298}$ of the species involved, normalized to an arbitrary standard, as a function of ionic radius. The standard chosen for the bottom plot in Figure 4 is the isomer M, because it is present over the whole lanthanide series. Because for a single cation only one of the three constants $K_{i}$ is observed, the two missing ones were calculated for all of the cations from eq 1 using the corresponding fitted parameters $C$ and $A_{i}$. The calculated equilibrium constants for the dissociation of the inner sphere water of the $\mathrm{m}$ isomer $\left(\mathrm{m} \leftrightarrow \mathrm{m}^{\prime}\right.$ equilibrium $),\left[\mathrm{m}^{\prime}\right] /[\mathrm{m}]$ $=K_{2} / K_{1}$, are about $10^{-3}$ and quite constant over the lanthanide series, including Sc. On the contrary, the calculated equilibrium constants for the loss of the inner sphere water molecule from 
Table 1. Reaction Enthalpies, Entropies, and Volumes for the Isomer Equilibrium Reaction $\mathrm{m} \Leftrightarrow \mathrm{M}$ (No Change of Coordination Number) of Ln(DOTA $)^{-}$Complexes $\left(K_{1}=[\mathrm{M}] /[\mathrm{m}]\right)$

\begin{tabular}{lcccc}
\hline$\left[\mathrm{Ln}(\mathrm{DOTA})\left(\mathrm{H}_{2} \mathrm{O}\right)\right]^{-}$ & $K_{1}^{298}$ & $\Delta H^{\circ} /\left(\mathrm{kJ} \mathrm{mol}^{-1}\right)$ & $\Delta S^{\circ} /\left(\mathrm{J} \mathrm{mol}^{-1} \mathrm{~K}^{-1}\right)$ & $\Delta V^{\text {oa }}$ \\
\hline $\mathrm{La}$ & 0.02 & $b$ & $b$ & $b$ \\
$\mathrm{Pr}$ & 0.19 & $+8.5 \pm 0.3$ & $-38 \pm 1$ & $-1.7 \pm 0.5(273.7 \mathrm{~K})^{c}$ \\
$\mathrm{Nd}$ & 0.84 & $-0.4 \pm 3.3$ & $b$ & $b$ \\
$\mathrm{Sm}$ & 2.00 & $b$ & $+1 \pm 1$ & $b$ \\
$\mathrm{Eu}$ & 3.30 & $-3.4 \pm 0.3$ & $+11 \pm 2$ & $-0.5 \pm 0.6(301.0 \mathrm{~K})^{c}$ \\
$\mathrm{Eu}$ & 4.36 & $-0.3 \pm 0.8$ & $+4 \pm 3$ & $b$ \\
$\mathrm{Eu}+2 \mathrm{M} \mathrm{NaCl}^{c}$ & 2.44 & $-1.0 \pm 0.9$ & $b \pm 3$ & $b$ \\
$\mathrm{Eu}+2 \mathrm{M} \mathrm{NaClO}_{4}{ }^{c}$ & 2.10 & $-1.0 \pm 1.0$ & $b$ & $b$ \\
$\mathrm{~Tb}$ & 13.2 & $b$ & $b$ & $b$ \\
$\mathrm{Dy}$ & 15.5 & $b$ & $b$ & $b$
\end{tabular}

${ }^{a}$ The temperature at which the volumes have been measured is indicated in brackets. ${ }^{b}$ Not measured. ${ }^{c}$ Measurements in Lausanne.

Table 2. Reaction Enthalpies, Entropies and Volumes for the Isomer Equilibrium Reaction $\mathrm{M} \Leftrightarrow \mathrm{m}^{\prime}$ (Change of Coordination Number from 9 to 8$)$ of $\operatorname{Ln}(\text { DOTA })^{-}$Complexes $\left(K_{2}=\left[\mathrm{m}^{\prime}\right] /[\mathrm{M}]\right)$

\begin{tabular}{ccccc}
\hline$\left[\operatorname{Ln}(\text { DOTA })\left(\mathrm{H}_{2} \mathrm{O}\right)_{x}\right]^{-}$ & $K_{2}{ }^{298}$ & $\Delta H^{\circ} /\left(\mathrm{kJ} \mathrm{mol}^{-1}\right)$ & $\Delta S^{\circ} /\left(\mathrm{J} \mathrm{mol}^{-1} \mathrm{~K}^{-1}\right)$ & $\Delta V^{\circ a}$ \\
\hline $\mathrm{Y}$ & 0.01 & $b$ & $b$ & $b$ \\
$\mathrm{Er}$ & 0.03 & $b$ & $33 \pm 3$ & $b$ \\
$\mathrm{Tm}$ & 0.08 & $16.2 \pm 0.9$ & $45 \pm 2$ & $b$ \\
$\mathrm{Yb}$ & 0.20 & $17.5 \pm 0.7$ & $18 \pm 1$ & $9.0 \pm 0.4(303.1 \mathrm{~K})^{c}$ \\
$\mathrm{Lu}$ & 0.18 & $10.1 \pm 0.1$ & $b$ & $15 \pm 2(273.0 \mathrm{~K})^{c}$ \\
$\mathrm{Sc}^{d}$ & 5.67 & $b$ & & $-5 \pm 5$
\end{tabular}

${ }^{a}$ The temperature at which the volumes have been measured is indicated in brackets. ${ }^{b}$ Not measured. ${ }^{c}$ Measuments in Lausanne. ${ }^{d}$ The $K^{298}$ value for $\mathrm{Sc}(\mathrm{III})$ is for $K_{3}=\left[\mathrm{M}^{\prime}\right] /\left[\mathrm{m}^{\prime}\right]$.

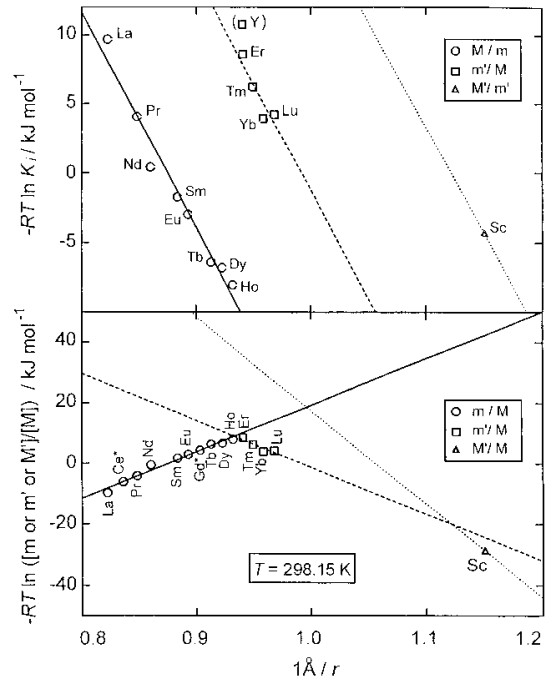

Figure 4. (Top) Calculated values of Gibbs free energies corresponding to the isomer equilibrium constants $K_{1}$ (full line), $K_{2}$ (broken line), and $K_{3}$ (dotted line). (Bottom) Isomer stabilities of $\mathrm{m}$ (full line), $\mathrm{m}^{\prime}$ (broken line), and $\mathrm{M}^{\prime}$ (dotted line) referred to $\mathrm{M}$ as a function of inverse ionic radius of the cation $\left(K_{1}=[\mathrm{M}] /[\mathrm{m}]\right.$ (circles); $K_{2}=\left[\mathrm{m}^{\prime}\right] /[\mathrm{M}]$ (squares); $K_{3}=\left[\mathrm{M}^{\prime}\right] /\left[\mathrm{m}^{\prime}\right]$ (triangles)). The lines correspond to a least squares fit to eq 1 . Y is plotted but is not part of the fit, as its coordination properties do not correspond to its ionic radius if compared to the trivalent lanthanides.

the $\mathrm{M}$ isomer $\left(\mathrm{M} \leftrightarrow \mathrm{M}^{\prime}\right.$ equilibrium), $\left[\mathrm{M}^{\prime}\right] /[\mathrm{M}]=K_{2} K_{3}$, changes drastically from $2.02 \times 10^{-13}$ for La to $9.90 \times 10^{4}$ for Sc. This results from the greater steric constraint of the water binding site in the chelates with the conformations $\mathrm{M}$ and $\mathrm{M}^{\prime}$, of smaller ligand cavity size than in the conformations $\mathrm{m}$ and $\mathrm{m}^{\prime}$. The observed and calculated $K_{i}$ values for all cations were then used to construct the plots of Figure 4 (bottom). The plotted constants are then $[\mathrm{m}] /[\mathrm{M}]=1 / K_{1}$ (full line), $\left[\mathrm{m}^{\prime}\right] /[\mathrm{M}]=K_{2}$ (broken line), and $\left[\mathrm{M}^{\prime}\right] /[\mathrm{M}]=1 / K_{1}$ (dotted line). The experimental constants from La to Ho fall in the first line, from Er to Lu on the second, and for Sc in the third. All of the calculated constants (not shown) lay well in the corresponding lines of the graph. The same eq 1 as that for the top plot of Figure 4 has been used to plot the data points in the bottom, but with inverted signs of the slope $(C)$ and $y$-intercept $\left(A_{1}\right)$ for the full line (stability of $\mathrm{m})$. The broken line is exactly the same as in the top part (stability of $\mathrm{m}^{\prime}$ ). The pointed line (stability of $\mathrm{M}^{\prime}$ ) has a slope of $C=-309 \pm 2 \AA^{-1}$ and an intercept of $A_{3}=+326 \pm 2 \mathrm{~kJ}$ $\mathrm{mol}^{-1}$.

The crossover between the relative stabilities of $\mathrm{m}$ and $\mathrm{M}$ is visible at $\mathrm{Nd}$ (where the stability of $\mathrm{m}$ crosses zero); thus, from La to Ho the observed equilibrium is $\mathrm{m} \leftrightarrow \mathrm{M}$, with the constant $K_{1}$. The crossover between $\mathrm{m}$ and $\mathrm{m}^{\prime}$ happens at Ho. This means that $\mathrm{m}^{\prime}$ becomes more stable than $\mathrm{m}$ with respect to $\mathrm{M}$ for lanthanides heavier than Ho, even if $\left[\mathrm{m}^{\prime}\right] /[\mathrm{m}]$ is about $10^{-3}$ across the entire lanthanide series (including $\mathrm{Sc}$ ), and for $\mathrm{Er}$ (Y) to Lu one observes $\mathrm{M} \leftrightarrow \mathrm{m}^{\prime}$ with constant $K_{2}$. For $\mathrm{Sc}$ one observes $\mathrm{m}^{\prime} \leftrightarrow \mathrm{M}^{\prime}$ with constant $K_{3}$, but the stability of interest is that of $\mathrm{M}^{\prime}$ with respect to $\mathrm{M}$, which can be calculated as described above. For Sc the $\mathbf{M}^{\prime}$ isomer is indeed much more stable than the $\mathrm{M}$ isomer, as can be seen from the strongly negative value of $-R T \ln \left(\left[\mathrm{m}^{\prime}\right] /[\mathrm{m}]\right)=-24.2 \mathrm{~kJ} \mathrm{~mol}^{-1}$. It is in equilibrium with the $\mathrm{m}^{\prime}$ isomer, $\mathrm{M}^{\prime}$ being the more stable species. These observations show that the assumption of the equilibria in Figure 2 is self-consistent. They were thus worth to be tested by variable-pressure experiments.

Variable Pressure Studies. As changes in coordination number across the lanthanide series have already been observed before, ${ }^{21}$ a variable-pressure ${ }^{1} \mathrm{H}$-NMR study to test the presence of coordination equilibria in the complexes was undertaken. In this way, $\Delta V^{\circ}$ values for the isomerization process were determined for some $\operatorname{Ln}(\mathrm{DOTA})^{-}$complexes along the series. Among the lighter $\operatorname{Ln}(\text { DOTA })^{-}$complexes, $\mathrm{Nd}(\mathrm{DOTA})^{-}$and $\mathrm{Eu}(\mathrm{DOTA})^{-}$(equilibrium $\mathrm{m} \leftrightarrow \mathrm{M}$ ) have been investigated, as well as $\mathrm{Yb}(\mathrm{DOTA})^{-}$and $\mathrm{Lu}(\mathrm{DOTA})^{-}$(equilibrium $\mathrm{M} \leftrightarrow \mathrm{m}^{\prime}$ ) for the heavier ones. The spectra obtained between 0.5 and $200 \mathrm{MPa}$ show a marked difference between the the effects of pressure on the isomer equilibria of the various DOTA complexes: for the $\mathrm{Nd}(\mathrm{III})$ and $\mathrm{Eu}(\mathrm{III})$ complexes, the position

(21) (a) Cossy, C.; Barnes, A. C.; Enderby, J. E.; Merbach, A. E. J. Chem. Phys. 1988, 90, 3254. (b) Kowall, T.; Foglia, F.; Merbach, A. E. J. Am. Chem. Soc. 1995, 117, 3790. 
of the equilibrium was virtually not affected by pressure, but there was a strong shift on the equilibrium for the $\mathrm{Yb}(\mathrm{III})$ and Lu(III) complexes.

The effect of pressure on a chemical equilibrium may be described by eq 2 , where $K_{i p}$ is the equilibrium constant at pressure $P, K_{i 0}$ the equilibrium constant at zero pressure, $\Delta V^{\circ}$ the reaction volume, $R$ the universal gas constant, and $T$ the temperature. Thus, measuring the equilibrium constant $K_{i}$ as a

$$
\ln \left(K_{i p}\right)=\ln \left(K_{i 0}\right)-\left(\Delta V^{\circ} P / R T\right) \quad(i=1,2)
$$

function of pressure allows the determination of $\Delta V^{\circ}$. The data were plotted as $R T \ln \left(K_{i p} / K_{i 0}\right)$ versus $P$ and least-squares-fitted to eq 2, with $K_{i 0}$ and $\Delta V^{\circ}$ as the fitted parameters (see Supporting Information). $\Delta V^{\circ}$ values are shown in Tables 1 and 2. The definition of the equilibrium constants $K_{i p}$ and $K_{i 0}$ along the lanthanide series is the same as that described above. The measured reaction volumes for the isomerization process were $-1.7 \pm 0.5$ and $-0.5 \pm 0.6 \mathrm{~cm}^{3} / \mathrm{mol}$ for $\mathrm{Nd}$ (DOTA) ${ }^{-}$ and $\mathrm{Eu}(\mathrm{DOTA})^{-}$, respectively, and $+9.0 \pm 0.4$ and $+15 \pm 2$ $\mathrm{cm}^{3} / \mathrm{mol}$ for $\mathrm{Yb}$ (DOTA) ${ }^{-}$and $\mathrm{Lu}(\mathrm{DOTA})^{-}$, respectively. Referring to Figure 2, these data clearly indicate that the isomerization process for the $\mathrm{Nd}(\mathrm{III})$ and $\mathrm{Eu}(\mathrm{III})$ complexes takes place without any change of the coordination number, through an $\mathrm{m}$ $\leftrightarrow \mathrm{M}$ equilibrium which only involves ligand rearrangement in the complex, whereas the isomerization process for the $\mathrm{Yb}$ (III) and $\mathrm{Lu}(\mathrm{III})$ complexes proceeds with the decrease of the lanthanide coordination number from 9 to 8 , most probably as dissociation of a water molecule, such as in the $\mathrm{M} \leftrightarrow \mathrm{m}^{\prime}$ transformation. In fact, such a dissociative reaction should show a positive reaction volume of about $10 \mathrm{~cm}^{3} / \mathrm{mol}$, the molar volume of water of $18 \mathrm{~cm}^{3} / \mathrm{mol}$, minus the contraction of the complex. In fact, the reaction volume for the equilibrium $\left[\mathrm{Eu}(\text { EDTA })\left(\mathrm{H}_{2} \mathrm{O}\right)_{3}\right]^{-} \leftrightarrow\left[\mathrm{Eu}(\text { EDTA })\left(\mathrm{H}_{2} \mathrm{O}\right)_{2}\right]^{-}+\mathrm{H}_{2} \mathrm{O}$, determined by UV-vis spectrophotometry, is $\Delta V^{\circ}=+13.2 \pm 0.2$ $\mathrm{cm}^{3} / \mathrm{mol}{ }^{16 \mathrm{~d}}$ It might be reasonably supposed that the carboxylate arms are getting closer together as the metal ion is getting smaller, and the water molecule is expelled from the inner coordination sphere, in a process which can be written as $\left[\operatorname{Ln}(\text { DOTA })\left(\mathrm{H}_{2} \mathrm{O}\right)\right]^{-} \leftrightarrow[\mathrm{Ln}(\text { DOTA })]^{-}+\mathrm{H}_{2} \mathrm{O}$ for $\mathrm{Ln}=\mathrm{Yb}$, $\mathrm{Lu}$. These data again point out that the isomer equilibrium along the whole lanthanide series is more complex than a simple $m$ $\leftrightarrow$ M process.

The isomer equilibrium proposed above for Sc(DOTA) ${ }^{-}$, $\mathrm{m}^{\prime} \leftrightarrow \mathrm{M}^{\prime}$, was also investigated by high-pressure proton NMR, as it should give a reaction volume $\Delta V^{\circ}$ close to zero. However, experimental difficulties in obtaining sufficiently good base line separation of the signals from the two isomers in the spectra obtained with the high-pressure probe yielded an experimental value for the rection volume with quite a high uncertainty, -5 $\pm 5 \mathrm{~cm}^{3} / \mathrm{mol}$. In spite of this, the fact that the reaction volume is not large and positive indicates that the two isomers of $\mathrm{Sc}(\mathrm{DOTA})^{-}$, as opposed to those of $\mathrm{Lu}(\mathrm{DOTA})^{-}$, have the same water coordination number, supporting the proposed isomer equilibrium $\mathrm{m}^{\prime} \leftrightarrow \mathrm{M}^{\prime}$.

Variable-Temperature Studies. Inspection into the temperature dependence of isomer ratios for the various complexes along the lanthanide series provided further support to the scheme of Figure 2. A typical van't Hoff behavior has been observed for the complexes of Pr, Nd, Eu, Tm, Yb, and $\mathrm{Lu}$ for which two isomers could be easily detected (see Supporting Information). A temperature dependence study of the other chelates was hindered by the very small intensity of the signals from one of the isomers present.

Particularly useful for gaining some insight into the difference between the $\mathrm{m}$ and $\mathrm{m}^{\prime}$ species was the evaluation of the enthalpic and entropic contributions to the equilibrium constants $K_{1}$ and $K_{2}$ (as defined above) as a function of the ionic radius of the lanthanide. The values of $\Delta H^{\circ}$ and $\Delta S^{\circ}$ for those equilibria, obtained from the temperature dependent ${ }^{1} \mathrm{H}-\mathrm{NMR}$ spectra, are shown in Tables 1 and 2 . From the thermodynamic point of view, the equilibrium reaction $\mathrm{M} \leftrightarrow \mathrm{m}^{\prime}$ appears to be slightly more endothermic than the $\mathrm{m} \leftrightarrow \mathrm{M}$ reaction. More important, it is accompanied by a large positive entropy change, which is conversely very small for the $\mathrm{m} \leftrightarrow \mathrm{M}$ isomerization. This finding, together with the evidence from high-pressure NMR discussed above, supports the view expressed in Figure 2 that the $\mathrm{M} \leftrightarrow \mathrm{m}^{\prime}$ equilibrium involves the fast dissociation of a water molecule and a slow rearrangement of the ligand conformation. It should be noticed that $\mathrm{M}$ and $\mathbf{M}^{\prime}$, as $\mathrm{m}$ and $\mathrm{m}^{\prime}$, are not distinguishable by proton NMR, due to the fast process of association/dissociation of the water molecule.

Variable Ionic Strength Studies. It has previously been observed that adding inorganic salts to solutions of $\operatorname{Ln}\left(\right.$ DOTA) ${ }^{-}$ complexes modifies the relative concentrations of the isomers present. ${ }^{19,22,23}$ In this study, we followed the effect of increasing concentrations of various inorganic salts $(\mathrm{NaF}, \mathrm{LiCl}, \mathrm{NaCl}$, $\mathrm{MgCl}_{2}, \mathrm{NaClO}_{4}, \mathrm{NaBr}$, and $\mathrm{KI}$ ) on the isomer equilibrium of the $\mathrm{Ce}(\mathrm{DOTA})^{-}, \mathrm{Eu}(\mathrm{DOTA})^{-}$, and $\mathrm{Yb}$ (DOTA) ${ }^{-}$complexes, by observing the effects on the relative intensity, line widths, and shifts of the proton NMR resonances of the isomers present. The effects of the salts studied were of two different kinds: whereas addition of $\mathrm{NaF}$ to $\mathrm{Ln}(\mathrm{DOTA})^{-}$affected the isomer equilibrium in some cases by formation of new chemical species separately observable by ${ }^{1} \mathrm{H}-\mathrm{NMR}$ spectroscopy, all of the other salts only changed the relative concentrations of the isomers present in solution.

Addition of $0.76 \mathrm{M} \mathrm{NaF}$ to a $0.10 \mathrm{M}$ solution of $\mathrm{Yb}(\mathrm{DOTA})^{-}$ at $\mathrm{pH} 7.6$ and $293 \mathrm{~K}$ (salt to complex mole ratio $\rho=$ [salt]/ $\left.\left[\operatorname{Ln}(\mathrm{DOTA})^{-}\right]=7.6\right)$ did not cause the appearance of new proton NMR signals in the spectrum of the solution, had no effect on the signals of the $\mathrm{m}^{\prime}$ isomer, but broadened and decreased the paramagnetic shifts of the signals from the $M$ isomer, in particular the most shifted protons $\mathrm{H}_{1}$ and $\mathrm{H}_{4}$ (data not shown). Thus, NaF interacts preferentially with the $\mathrm{M}$ isomer, bearing one inner sphere water molecule, rather than with the $\mathrm{m}^{\prime}$ isomer, with no inner sphere water. This interaction is weak, as the exchange process related to the fluoride binding is fast in the proton NMR time scale, with some exchange broadening at $293 \mathrm{~K}$.

In the case of $\mathrm{Eu}(\mathrm{DOTA})^{-}$the effect of $\mathrm{NaF}$ on the equilibrium between the $\mathrm{M}$ and $\mathrm{m}$ isomers is quite different. In $\mathrm{D}_{2} \mathrm{O}$ and at $270 \mathrm{~K}$, addition of $\mathrm{NaF}$ at the ratio $\rho=7.6$ causes a large decrease of intensity and broadening of the resonances of the isomer $\mathrm{m}$, while the signals from the $\mathrm{M}$ isomer show a decrease of intensity. At the same time, the signals of a new species appear in slow exchange with the others (see Supporting Information). No effect of $\mathrm{pH}$, between 8 and 12.5, was observed on the distribution of these species. Exchange between the different species is confirmed by a 2D-EXSY experiment at $271 \mathrm{~K}$ for the sample containing $\mathrm{Eu}(\mathrm{DOTA})^{-}$and $\mathrm{NaF}$, where exchange cross-peaks are observed between the protons of the $\mathrm{M}$ species and the new fluoride-bound species, whose resonances were assigned from the exchange patterns observed (see Supporting Information). The 2D-EXSY spectrum obtained in this study shows that each proton of $M$ and of the fluoride

(22) Marques, M. P. M.; Geraldes, C. F. G. C.; Sherry, A. D.; Merbach, A. E.; Powell, D. H.; Pubanz, D.; Aime, S.; Botta, M. J. Alloys Compd. 1995, 225, 303.

(23) Jacques, V.; Comblin, V.; Gilsoul, D.; Desreux, J. F. Book of Abstracts, 17th International Symposium on Macrocyclic Chemistry, Provo, Utah, 1992; Paper P44. 
derivative displays exactly the same pattern of exchange crosspeaks as those observed before for $\mathrm{Eu}(\mathrm{DOTA})^{-}(\mathrm{M} \leftrightarrow \mathrm{m}$ exchange $)^{19,24}$ and for $\mathrm{Yb}(\mathrm{DOTA})^{-}\left(\mathrm{M} \leftrightarrow \mathrm{m}^{\prime}\right.$ exchange $) ;{ }^{8,24}$ namely, each proton of each isomer features three cross-peaks. Thus, it may be concluded that the replacement of a water molecule by $\mathrm{F}^{-}$anion does not change the ligand conformation dynamics of the complexes. In the 2D-EXSY spectrum, the signals from the $\mathrm{m}$ isomer are so broad that only barely detectable exchange cross-peaks are produced with the other two species. Increasing the temperature to $298 \mathrm{~K}$ changes the proton spectrum, causing coalescence of the signals $\mathrm{ax}_{1}{ }^{\mathrm{m}}$ and $\mathrm{ax}_{1}{ }^{\mathrm{F}}$, of the isomer $\mathrm{m}$ and the fluoride derivative, respectively, whereas the signal $\mathrm{ax}_{1}{ }^{\mathrm{M}}$ of the isomer $\mathrm{M}$ at this temperature is exchange broadened but not coalesced. This result indicates that the $\mathrm{m} \leftrightarrow \mathrm{M}$ exchange process is slower than that of $\mathrm{m}$ with the fluoride derivative, but this later process is still slow on the proton NMR time scale at a temperature of $298 \mathrm{~K}$.

The occurrence of an inner sphere fluoride-bound complex for $\mathrm{Eu}(\mathrm{DOTA})^{-}$is supported by the comparison of the ${ }^{19} \mathrm{~F} \mathrm{NMR}$ signal line width of a $0.8 \mathrm{M}$ solution of $\mathrm{NaF}$ upon addition of Eu(DOTA) $)^{-}$, with the value obtained upon addition of $\mathrm{Eu}(\mathrm{TTHA})^{3-}(\mathrm{TTHA}=$ triethylenetetraaminehexaacetic acid $)$. At a $0.09 \mathrm{M}$ concentration of the first complex, the linewidth of the ${ }^{19} \mathrm{~F}$ NMR signal of $\mathrm{F}^{-}$is $70 \mathrm{~Hz}$, much higher than the value at the same concentration of the second complex $(20 \mathrm{~Hz})$, which only binds $\mathrm{F}^{-}$in an outer sphere mode. This is strong indication of the occurrence of exchange between bulk and inner sphere coordinated $\mathrm{F}^{-}$ions.

These results may be rationalized by the presence of the following equilibria for the interaction of the isomers of $\mathrm{Eu}(\mathrm{DOTA})^{-}$and $\mathrm{Yb}(\mathrm{DOTA})^{-}$with $\mathrm{F}^{-}$:

$$
\begin{aligned}
& \mathrm{M}+\mathrm{F}^{-} \leftrightarrow\left[\mathrm{M}^{\prime}-\mathrm{F}\right]^{2-}+\mathrm{H}_{2} \mathrm{O} \\
& \mathrm{m}+\mathrm{F}^{-} \leftrightarrow\left[\mathrm{m}^{\prime}-\mathrm{F}\right]^{2-}+\mathrm{H}_{2} \mathrm{O}
\end{aligned}
$$

with equilibrium constants $K_{\mathrm{M}}$ and $K_{\mathrm{m}}$, respectively, for the inner sphere replacement of an $\mathrm{H}_{2} \mathrm{O}$ molecule by an $\mathrm{F}^{-}$anion at the $\mathrm{M}$ and $\mathrm{m}$ isomers. The NMR experiments show that in the case of $\mathrm{Yb}(\mathrm{DOTA})^{-} \mathrm{m}^{\prime}$ does not interact with $\mathrm{F}^{-}$, while the $\mathrm{F}^{-}$-bound complex has a structure more like $\mathrm{M}$ than $\mathrm{m}$ and is represented by $\left[\mathrm{M}^{\prime}-\mathrm{F}\right]^{2-}$. For $\mathrm{Eu}(\mathrm{DOTA})^{-}$, the $\mathrm{F}^{-}$-bound complex has a structure more like $\mathrm{m}$ than $\mathrm{M}$ and is represented by $\left[\mathrm{m}^{\prime}-\mathrm{F}\right]^{2-}$. Thus, the formation of $\left[\mathrm{m}^{\prime}-\mathrm{F}\right]^{2-}$ occurs at much lower fluoride concentration than $\left[\mathrm{M}^{\prime}-\mathrm{F}\right]^{2-}$. As the forms $\mathrm{M}$, $\mathrm{m}^{\prime}$, and $\left[\mathrm{m}^{\prime}-\mathrm{F}\right]^{2-}$ are detected in solution, we conclude that $K_{\mathrm{m}}$ is much higher than $K_{\mathrm{M}}$. The binding preferences of the isomers to $\mathrm{F}^{-}$are in the order $\mathrm{m}>\mathrm{M}>\mathrm{m}^{\prime}$, which possibly reflects the higher acessibility of the more open structures to $\mathrm{F}^{-}$. The exchange processes observed indicate that the $\mathrm{F}^{-}$ exchange process $\mathrm{M} \leftrightarrow\left[\mathrm{M}^{\prime}-\mathrm{F}\right]^{2-}$ (eq 3 ) in the $\mathrm{Yb}^{3+}$ complex is faster than the exchange process $\mathrm{m} \leftrightarrow\left[\mathrm{m}^{\prime}-\mathrm{F}\right]^{2-}$ (eq 4) in the $\mathrm{Eu}^{3+}$ complex. This probably reflects that $K_{\mathrm{M}}\left(\mathrm{Yb}^{3+}\right) \ll$ $K_{\mathrm{m}}\left(\mathrm{Eu}^{3+}\right)$ due to the smaller ionic radius of the first cation. This hypothesis is corroborated by the fact that a dissociative exchange reaction is favored by steric crowding of the binding site of the exchanging ligands, as proven by the determination of rates and mechanisms of water exchange on [Ln(DTPABMA) $\left(\mathrm{H}_{2} \mathrm{O}\right)$ ] complexes. ${ }^{16 \mathrm{c}} \mathrm{As}$ the $\mathrm{m}$ and $\mathrm{M}$ isomers of $\left[\mathrm{Eu}(\mathrm{DOTA})\left(\mathrm{H}_{2} \mathrm{O}\right)\right]^{-}$and $\left[\mathrm{Yb}(\mathrm{DOTA})\left(\mathrm{H}_{2} \mathrm{O}\right)\right]^{-}$, respectively, are of coordination number nine, the water-fluoride exchange must take a dissociative pathway, which is accelerated on the $\mathrm{Yb}^{3+}$ complex, because the DOTA ligand closes itself tightly around the smaller metal ion, squeezing out the ninth ligand $\left(\mathrm{M} \leftrightarrow \mathrm{m}^{\prime}\right.$ equilibrium for $\mathrm{Yb}^{3+}, \mathrm{M} \leftrightarrow \mathrm{m}$ for $\mathrm{Eu}^{3+}$ ).

(24) Jacques, V.; Desreux, J. F. Inorg. Chem. 1994, 33, 4048.

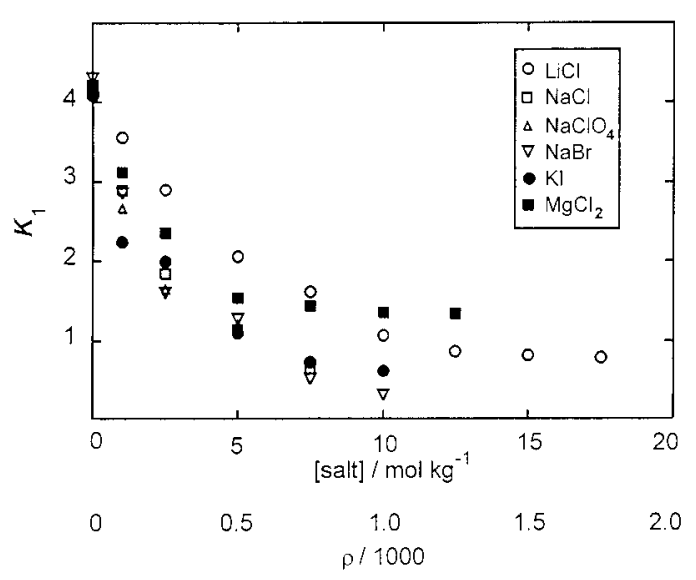

Figure 5. Dependence of the isomer equilibrium constant $K_{1}$ of $\left[\mathrm{Eu}(\text { DOTA })\left(\mathrm{H}_{2} \mathrm{O}\right)_{x}\right]^{-}$in $\mathrm{D}_{2} \mathrm{O}$ upon the ratio $\rho$ of salt to complex concentrations (0.01 M Eu(DOTA) $)^{-}$, pH 7.0, $\left.298 \mathrm{~K}\right)$.

A different kind of effect was observed upon addition of all of the other salts studied to solutions containing Eu(DOTA) ${ }^{-}$ or $\mathrm{Yb}(\mathrm{DOTA})^{-}$, namely, an increase of the intensity of the signals for the isomer with the smaller susceptibility anisotropy $\left(\mathrm{m}\right.$ for $\mathrm{Eu}(\mathrm{DOTA})^{-}, \mathrm{m}^{\prime}$ for $\mathrm{Yb}(\mathrm{DOTA})^{-}$) relative to the one with larger susceptibility anisotropy (M). Figure 5 shows a typical set of data for $\mathrm{Eu}(\mathrm{DOTA})^{-}$, where the equilibrium constant $K_{1}=[\mathrm{M}] /[\mathrm{m}]$ (given by the ratio of intensities of the $\mathrm{H}_{4}$ protons for the two isomers) is plotted against $\rho$. Exactly analogous data were obtained for the equilibrium constant $\left(K_{2}\right)^{-1}$ $=[\mathrm{M}] /\left[\mathrm{m}^{\prime}\right]$ for $\mathrm{Yb}(\mathrm{DOTA})^{-}$.

The effects of all salts are quite similar to each other, with the most significant change of isomer equilibrium for $\rho$ values up to 500 and a saturation of the effect for $\rho>1000$. Note that the effect of all of these salts is to stabilize the reverse antiprismatic structure of the ligand ( $\mathrm{m}$ or $\mathrm{m}^{\prime}$ ) relative to the prismatic. The relative magnitudes of the maximum effects of the different salts do not follow the trends of binding constants of the cations to carboxylate groups or of anions to the first coordination sphere of the $\operatorname{Ln}(\mathrm{III})$ cations. Thus, it seems that, for these salts, both the cation and the anion have a role in stabilizing the minor isomer structure, $\mathrm{m}$ or $\mathrm{m}^{\prime}$, even though $\mathrm{m}^{\prime}$ has no inner sphere water molecule.

In the case of the $\mathrm{Ce}(\mathrm{DOTA})^{-}$complex, only the $\mathrm{m}$ isomer is detected in $\mathrm{D}_{2} \mathrm{O}$ between 293 and $270 \mathrm{~K}$ in the absence of salt. The existence of the isomer $\mathrm{M}$ is only detected by a substantial exchange broadening of the $\mathrm{H}_{1}$ and $\mathrm{H}_{4}$ resonances of the isomer $\mathrm{m}$. However, at $270 \mathrm{~K}$ and down to $238 \mathrm{~K}$ in a $1: 1$ (volume) mixture of $\mathrm{CD}_{3} \mathrm{OD} / \mathrm{D}_{2} \mathrm{O}$ the two isomers are in the slow-exchange regime and both detectable. Comparison of the two spectra at $270 \mathrm{~K}$ in both solvents shows that the organic solvent favors the $\mathrm{M}$ isomer. Addition of the $\mathrm{LiCl}$ salt to the $\mathrm{Ce}(\text { DOTA })^{-}$aqueous sample at $293 \mathrm{~K}$ caused a sharpening of the proton signals of the $\mathrm{m}$ isomer, which reflects the disappearance of the residual $\mathrm{M}$ form from the solution, no longer causing exchange broadening upon the $\mathrm{m}$ resonances.

It would be reasonable to consider that the interaction of $\mathrm{Cl}^{-}$ ions with $\mathrm{Eu}(\mathrm{DOTA})^{-}$might occur through inner sphere binding of the anion and replacement of the water molecule, as described above for $\mathrm{F}^{-}$. However, in this case much lower $K_{\mathrm{m}}$ and $K_{\mathrm{M}}$ values are expected. These expectations are confirmed by the failure to observe experimentally any inner sphere $\mathrm{Cl}^{-}$-bound species by ${ }^{1} \mathrm{H}-\mathrm{NMR}$ spectroscopy, $[\mathrm{m}-\mathrm{Cl}]^{2-}$ or $[\mathrm{M}-\mathrm{Cl}]^{2-}$, in slow exchange with the others, as well as the observation of ${ }^{35} \mathrm{Cl}$ shifts of $\mathrm{Cl}^{-}$ions in the presence of $\mathrm{Ln}(\mathrm{DOTA}){ }^{-}$complexes 
which are devoid of a contact contribution. ${ }^{25}$ The fact that such a shift is dipolar and not zero shows that the $\mathrm{Cl}^{-}$ions do bind weakly, at the outer sphere, the $\operatorname{Ln}(\text { DOTA })^{-}$chelates, being oriented in an ionic interaction preferentially along the main symmetry axis of the complex, e.g., by hydrogen bonding with water molecules near the carboxylic groups in the complex.

The cations present in the salts also interact with the Ln(DOTA $)^{-}$complexes, as shown by the ${ }^{23} \mathrm{Na}$ dipolar shifts induced by the paramagnetic chelates upon the $\mathrm{Na}^{+}$ions, which interact with the four negatively charged bound carboxylate groups. ${ }^{25}$ The effect of $\mathrm{LiCl}$ on the Eu(DOTA) ${ }^{-}$isomer ratio has been previously observed, ${ }^{19}$ and the increased concentration of isomer $\mathrm{m}$ in the presence of $\mathrm{Li}^{+}$was assigned to a stronger interaction of this cation with the bound carboxylate groups of the form $\mathrm{m}$ than with those of $\mathrm{M}$; as in the former the $\mathrm{Ln}-\mathrm{O}$ bond is longer, and thus more polarized than in the latter. However, the absence of a correlation between the relative effects of the various salts upon the isomer equilibrium and the strength of binding of the cations and anions to the charged regions of the chelate shows that both species may play a role.

In order to better characterize the thermodynamic effect of the weakly binding salts upon the isomer equilibrium, we studied by ${ }^{1} \mathrm{H}$-NMR spectroscopy the temperature dependence of the isomer ratio of $\mathrm{Eu}(\mathrm{DOTA})^{-}$in the presence of the salts $\mathrm{NaClO}_{4}$ and $\mathrm{NaCl}$, which have a common cation and have anions which in one case (perchlorate) do not enter into the first coordination sphere and in the other may enter at least partially into it. The van't Hoff plots thus obtained yielded the thermodynamic parameters $\Delta H^{\circ}$ and $\Delta S^{\circ}$ shown in Table 1. Upon addition of both salts $\Delta H^{\circ}$ remains close to zero, whereas $\Delta S^{\circ}$ becomes less positive. Thus, the influence of these salts on the isomer equilibrium results from a decreased entropy effect, possibly related to weaker solvation of the isomers when the activity of water in the solutions containing high salt concentrations decreases. The effect of these non-coordinating salts does not result from a nonspecific perturbation of the solvent water structure, as both strong water structure forming salts like $\mathrm{MgCl}_{2}$ and $\mathrm{LiCl}$, or structure breaking salts like $\mathrm{KI},{ }^{29}$ show similar effects on the value of the isomerization constant $K_{1}$ (see Figure 5).

The strong decrease of the water activity in the presence of high salt concentrations might cause a shift of the isomer equilibrium to the $\mathrm{m}$ form via stabilization of the $\mathrm{m}^{\prime}$ form (without inner sphere water and indistinguishable from $\mathrm{m}$ by proton NMR). We tested this hypothesis by UV-visible spectroscopy of aqueous $\mathrm{Eu}(\mathrm{DOTA})^{-}$solutions as a function of salt concentration. Evidence of the existence of Eu(DOTA) ${ }^{-}$ isomers $\mathrm{M}$ and $\mathrm{m}$ with the same water coordination number has been observed from the luminescence excitation, emission and lifetime spectroscopy of its ${ }^{7} \mathrm{~F}_{0} \rightarrow{ }^{5} \mathrm{D}_{1}$ transition. ${ }^{27}$ However, the ${ }^{7} \mathrm{~F}_{0} \rightarrow{ }^{5} \mathrm{D}_{0}$ transition in the absorption spectrum is split into two components when the isomers involved have different coordination numbers, ${ }^{28}$ as shown before for various $\mathrm{Eu}^{3+}$ chelates. ${ }^{16 \mathrm{~d}, 28}$ Our spectra of $0.03 \mathrm{M} \mathrm{Eu}(\mathrm{DOTA})^{-}$in water at $313 \mathrm{~K}$ in the presence of $\mathrm{NaClO}_{4}$ concentrations up to $5.5 \mathrm{M}$ at $318 \mathrm{~K}$ did not show any splitting of that absorption band,

(25) Bryden, C. C.; Reilley, C. N.; Desreux, J. F. Anal. Chem. 1981, 53, 1418.

(26) Aime, S.; Botta, M.; Fasano, M. Unpublished results.

(27) Albin, M.; Horrocks, W. de W., Jr.; Liotta, F. J. Chem. Phys. Lett. 1982, 85, 61

(28) Kostromina, N. A.; Tananaeva, N. N. Russ. J. Inorg. Chem. 1971, $16,1256$.

(29) Hertz, H. G. In Water, A Comprehensive Treatise; Franks, F., Ed.; Plenum: New York, 1973; Vol. 3, p 301.

(30) Reilley, C. N.; Good, B. W.; Desreux, J. F. Anal. Chem. 1975, 47, 2110. showing that the presence of very high salt concentrations does not lead to complex species with no inner sphere water.

Thus, we conclude that the effects of the non-coordinating salts on the isomer equilibrium result from preferential stabilization of the more open and polarizable ligand conformation in the $\mathrm{m}$ and $\mathrm{m}^{\prime}$ forms relative to the $\mathrm{M}$ form. This could be due to weak outer sphere binding of the cations and/or anions ${ }^{19,23}$ or to decreased solvation of the isomeric forms due to the decreased activity of water.

Variable-Pressure Study on the Kinetics of the $\mathbf{M} \rightarrow \mathbf{m}$ Isomerization. Besides the influence on the position of the $\mathbf{M}$ $\leftrightarrow \mathrm{m}$ equilibrium, the influence of pressure on the rate of isomerization is of interest. The resulting activation volume permits one to conclude whether the system takes a direct $\mathrm{M}$ $\rightarrow \mathrm{m}$ or an indirect $\mathrm{M} \rightarrow \mathrm{M}^{\prime} \rightarrow \mathrm{m}^{\prime} \rightarrow \mathrm{m}$ pathway (see Figure 2). The latter possibility seemed more probable because, if the nine-coordinate ground state were too crowded to allow for an easy scrambling of the carboxylate arms, a diminution of the coordination number (dissociation of a carboxylate arm or, most probably because more frequent, of the inner sphere water molecule) could serve as the activation step. Though the dissociation of the water molecule in the step $\mathbf{M} \rightarrow \mathbf{M}^{\prime}$ (Figure 2) would be fast and thus not the rate determining step, pressure would shift the $\mathrm{M} \leftrightarrow \mathrm{M}^{\prime}$ equilibrium to the left and thus slow down the following step $\left(\mathbf{M}^{\prime} \rightarrow \mathrm{m}^{\prime}\right)$. In sum, the isomerization pathway $\mathrm{M} \rightarrow \mathrm{M}^{\prime} \rightarrow \mathrm{m}^{\prime} \rightarrow \mathrm{m}$ would be slowed down by pressure (positive activation volume), while pressure would have negligible influence (near-zero activation volume) on the direct $\mathrm{M} \rightarrow \mathrm{m}$ pathway, which does not involve a change of coordination number.

The pressure effect on the line widths of protons $\mathrm{H}_{4}$ and $\mathrm{H}_{4}$ of $\left[\mathrm{Eu}(\mathrm{DOTA})\left(\mathrm{H}_{2} \mathrm{O}\right)\right]^{-}$was measured at $305.5 \mathrm{~K}$ between 0.6 and $200 \mathrm{MPa}$. The measured line widths at this temperature were corrected for the paramagnetic broadening $\left(35 \mathrm{~Hz}\right.$ for $\mathrm{H}_{4}$ and $37 \mathrm{~Hz}$ for $\mathrm{H}_{4^{\prime}}$, measured at $269.0 \mathrm{~K}$ ) and the width of the water signal $(10 \mathrm{~Hz}$, including the exponential broadening of $4.0 \mathrm{~Hz}$ applied in order to improve the signal to noise ratio). The exchange broadening $\left(37 \pm 3 \mathrm{~Hz}\right.$ for $\mathrm{H}_{4}$ and $161 \pm 10 \mathrm{~Hz}$ for $\mathrm{H}_{4^{\prime}}$ ) did not change significantly with pressure. With populations of 81 and $19 \%$ for $\mathrm{H}_{4}$ and $\mathrm{H}_{4^{\prime}}$, respectively, a fit of the residence times in the slow-exchange limit yielded an activation volume of $\Delta V^{\ddagger}=+0.6 \pm 0.4 \mathrm{~cm}^{3} / \mathrm{mol}$ and an exchange rate for $\mathrm{m} \rightarrow \mathrm{M}$ at zero pressure and $305.5 \mathrm{~K}$ of $k\left(4^{\prime}\right.$ $\rightarrow 4)_{0}^{306}=511 \pm 10 \mathrm{~s}^{-1}$. This result suggests that the isomerization $\mathrm{M} \rightarrow \mathrm{m}$ takes the direct pathway.

\section{Discussion}

The experimental data concerning a thorough proton NMR study of the effect of cationic radius, temperature, pressure, and ionic strength upon the isomer equilibrium for the $\operatorname{Ln}(\text { DOTA })^{-}$ chelates along the lanthanide series clearly shows that the twostate $\mathrm{m} \leftrightarrow \mathrm{M}$ equilibrium previously adopted ${ }^{8,19,24}$ is not correct. Although X-ray crystal structures exist for the $\mathrm{M}$ and $\mathrm{m}$ ligand conformations, ${ }^{2-4,15}$ the ionic radius dependence of the enthalpy, entropy, and reaction volumes observed clearly shows the existence of an isomer $\mathrm{m}^{\prime}$ in solution with no inner sphere water. Figure 2 shows the isomer equilibrium proposed in this work, which can rationalize the data.

The isomers would have cavity sizes decreasing in the order $\mathrm{m}>\mathrm{M}>\mathrm{m}^{\prime}>\mathrm{M}^{\prime}$, and they predominate in this order as the $\mathrm{Ln}$ (III) ion radius decreases: the $\mathrm{m}$ structure is observed from the $\mathrm{La}(\mathrm{III})$ to the $\mathrm{Dy}(\mathrm{III})$ complex but predominates until $\mathrm{Nd}(\mathrm{III})$; the $\mathrm{M}$ structure is present from $\mathrm{La}(\mathrm{III})$ to $\mathrm{Lu}(\mathrm{III})$ and is most stable at $\mathrm{Ho}(\mathrm{III})$; the $\mathrm{m}^{\prime}$ form appears from $\mathrm{Er}(\mathrm{III})$ to $\mathrm{Lu}(\mathrm{III})$. The $\mathrm{M}^{\prime}$ structure is not observed for the Ln(III) complexes, but 
we claim to observe its presence in the $\mathrm{Sc}(\mathrm{DOTA})^{-}$complex, where it predominates relative to $\mathrm{m}^{\prime}$.

In the cases of all the paramagnetic chelates of the lanthanides, except $\mathrm{Tm}(\mathrm{III})$, the $\mathrm{M}$ isomer has the larger susceptibility anisotropy relative to the other isomer $\left(\mathrm{m}\right.$ or $\left.\mathrm{m}^{\prime}\right)$. The abnormally high paramagnetic shifts for the $\mathrm{Tm}(\mathrm{III}) \mathrm{m}^{\prime}$ isomer could be related to changes in the crystal field parameter $A_{0}^{2}$, which have been reported for the $\operatorname{Ln}(\mathrm{DOTP})^{5-}$ chelates $(\mathrm{Tb}-$ $\mathrm{Yb}$ ), where this parameter has the largest value for Tm(III). ${ }^{31}$

The structural changes involved on going from $\mathrm{m}$ to $\mathrm{M}$ to $\mathrm{m}^{\prime}$ need to be characterized. As anticipated above, from the analysis of the dipolar shift of ${ }^{1} \mathrm{H}$ resonances of the minor isomer of $\mathrm{Yb}(\mathrm{DOTA})^{-}$we know that the DOTA ligand is wrapping the $\mathrm{Ln}(\mathrm{III})$ ion in a distorted square-antiprismatic geometry inverted with respect to that of the major $\mathrm{M}$ isomer and with a smaller tilt angle. ${ }^{8}$ The coordination of the ligand in the minor isomer of $\mathrm{Yb}(\mathrm{DOTA})^{-}$has a noticeable similarity to that found in the X-ray structure determination of $\mathrm{La}(\mathrm{DOTA})^{-}$and of other related complexes..$^{9-12,15}$ However, according to Figure 3, $\mathrm{La}(\mathrm{DOTA})^{-}$corresponds to an $\mathrm{m}$ isomer, whereas, from the analysis of the molar fractions of the occurring isomers, we assigned an $\mathrm{m}^{\prime}$ structure to the minor isomer of $\mathrm{Yb}(\mathrm{DOTA})^{-}$. On the basis of these considerations it seems likely that only minor structural differences of the arrangement of the ligand around the $\mathrm{Ln}(\mathrm{III})$ ions must occur between complexes endowed with $\mathrm{m}$ or $\mathrm{m}^{\prime}$ structures.

Importantly, $\mathrm{m}$ and $\mathrm{m}^{\prime}$ species are not distinguishable from their high-resolution NMR spectra (the minor differences may arise from temperature effects on proton shifts), as $\mathrm{m}$ and $\mathrm{m}^{\prime}$ do not seem to be different in the conformation of the ligand around the $\mathrm{Ln}$ (III) ion, although the coordination geometry of the cation in the complex is different. This is supported by our previous observation ${ }^{22}$ that the contact/dipolar shift separation plots ${ }^{30}$ obtained for the proton and ${ }^{13} \mathrm{C}$ resonances of the major and minor isomers do not show any large deviations from linearity, although the minor isomer changes from $\mathrm{m}$ to $\mathrm{m}^{\prime}$ along the lanthanide series.

By taking into account this finding together with the evidence discussed above that $\mathrm{m}$ and $\mathrm{m}^{\prime}$ have to be isostructural, it seems reasonable that the second equilibrium involves the dissociation of a water molecule and the rotation of the $\mathrm{O}_{4}$ square along the symmetry axis, going from an enneacoordinate $M$ to an octacoordinate $\mathrm{m}^{\prime}$.

Previous work on the water exchange rates of lanthanide(III) complexes in general and of poly(amino carboxylates) in particular gave strong evidence that the activation energy for the exchange reaction of water molecules bound to the inner coordination sphere is very small. ${ }^{16,21}$ Such an exchange process is then fast on the proton NMR time scale so that two isomers differing only in the water coordination number and with the same ligand conformation, such as $\mathrm{m}$ and $\mathrm{m}^{\prime}$, are not distinguishable by proton NMR. The interconversion between the isomers $\mathrm{M}$ and $\mathrm{m}$, with the same coordination numbers and the same number of inner sphere water molecules but different ligand conformations, is slow on the ${ }^{1} \mathrm{H}-\mathrm{NMR}$ time scale. The interconversion between $\mathrm{M}$ and $\mathrm{m}^{\prime}$ takes place through a slow ligand conformation change and a fast addition (loss) of an inner sphere water molecule. It is conceivable that a fourth isomer, $\mathrm{M}^{\prime}$, with no water coordination and the same ligand conformation as M, may exist, but it would be indistinguishable from $\mathrm{M}$ in the proton NMR time scale. The $\mathrm{M}^{\prime} \leftrightarrow \mathrm{m}^{\prime}$ equilibrium might be present for the $\mathrm{Sc}(\mathrm{DOTA})^{-}$complex, as two isomers are present in the aqueous solutions of this complex, as described before. This equilibrium would be detectable by high pressure

(31) Ren, J.; Sherry, A. D. J. Magn. Reson. 1996, B111, 178.
$\mathrm{NMR}$, with $\Delta V^{\circ} \sim 0$, as no change of coordination number would be expected.

The two helicities possible within a square-antiprismatic geometry of the $\operatorname{Ln}(\mathrm{DOTA})^{-}$complexes (one belonging to the macrocycle and the other to the orientation of the acetate arms) can, in principle, originate two enantiomeric pairs of diastereoisomers, whose possible interconversions are represented in Figure 1. $\mathrm{M}$ and $\mathrm{m}$ isomers exchange slowly in solution on the NMR time scale. ${ }^{8}$ Isomerization may occur either by helicity inversion of the ethylenic moieties in the macrocyclic ring (by maintaining the helicity of the acetate arms) or by the motion of the acetate arms (by keeping "frozen" the macrocycle). Racemization requires the occurrence of both motions. Variable-temperature ${ }^{1} \mathrm{H}-\mathrm{NMR}$ spectra of $\operatorname{Pr}(\mathrm{DOTA})$ and Nd(DOTA) clearly showed that the exchange between $\mathrm{M}$ and $\mathrm{m}$ diastereoisomers (isomerization) precedes the exchange between the enantiomers (racemization). ${ }^{8}$ However, these observations were unable to ascertain whether the isomerization occurs through the motion of the acetate arms or through configuration inversion of the ring itself. Later, determination of the exchange rates in $\mathrm{Yb}(\mathrm{DOTA})^{-}$with two-dimensional exchange spectroscopy (2D-EXSY) by Jacques and Desreux ${ }^{24}$ established that the two considered motions take place at a similar rate, indicating the possible occurrence of a synchronous motion. This conclusion has been recently questioned by the results obtained from band shape analysis of the variable-temperature ${ }^{13} \mathrm{C}-\mathrm{NMR}$ spectra of the closely related, diamagnetic $\operatorname{Lu}(\mathrm{DOTA})^{-}$, showing that, also in this case, isomerization is faster than enantiomerization. $^{4}$

In this work we are unable to conclude whether the $\mathrm{M} \leftrightarrow \mathrm{m}$ and $\mathrm{M} \leftrightarrow \mathrm{m}^{\prime}$ transformations occur through the same rearrangement process ${ }^{8,19,24}$ (i.e., inversion of the cycle helicity or motion of the acetate arms) or not. However, the reaction entropies and volumes measured clarify that there is a loss of a coordinated water molecule on going from $\mathrm{M}$ to $\mathrm{m}^{\prime}$ species, but not on going from $\mathrm{M}$ to $\mathrm{m}$ species. With regard to the $\mathrm{M}$ to $m$ transformation, the near-zero activation volume observed suggests that this process takes the direct pathway (Corey twist) in spite of the high coordination number of nine, which would be thought to cause a highly energetic activated state. Thus, the coordination sphere rearrangement does not occur through an intermediate with a coordination number of eight, either by dissociation of an acetate or a water oxygen of M. Although the loss of a water molecule is much faster than the ligand rearrangement, the $\mathrm{M}$ isomer transforms into $\mathrm{m}^{\prime}$ via $\mathrm{m}$ (ligand rearrangement) followed by water dissociation.

The rates obtained for the conformational rearrangement $\mathrm{M} \leftrightarrow$ $m$ of $\left[\mathrm{Eu}(\mathrm{DOTA})\left(\mathrm{H}_{2} \mathrm{O}\right)\right]^{-}$and for the exchange of the inner sphere with bulk water together with the relative stabilities of the different species (Figure 4) and the support of the variablepressure studies (Tables 1 and 2) allow one to trace the semiquantitative energy diagram of Figure 6, which together with Figure 2 gives the full mechanistic description of the solution behavior of DOTA complexes with trivalent lanthanides. The shadowed regions in Figure 6 give the energy range covered by the complexes across the series for each isomer according to Figure 4 (bottom). The limits are found for the smallest and the biggest lanthanide ions, i.e. $\mathrm{Lu}^{3+}$ and $\mathrm{La}^{3+}$, with $\mathrm{Gd}^{3+}$ approximately in the middle. The calculated $G$ values are the result of numerous assumptions (e.g., the experimental equilibrium constants data are only those corresponding to the data points in Figure 4 (top)) and have to be interpreted with the utmost care. The essential feature of the diagram is that the $\mathrm{m}, \mathrm{M}$, and $\mathrm{m}^{\prime}$ isomers have comparable 


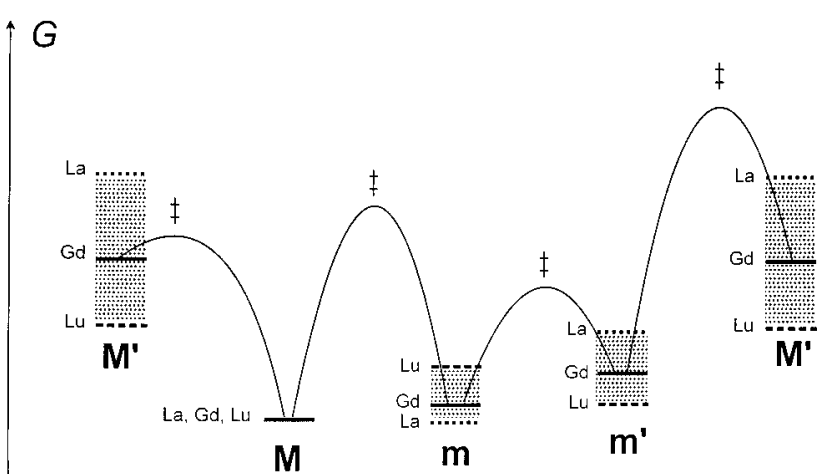

Figure 6. Gibbs free energies $-R T \ln K_{i}$ for equilibria $\mathrm{m} \leftrightarrow \mathrm{M}(1 /$ $\left.K_{1}\right), \mathrm{M} \leftrightarrow \mathrm{m}^{\prime}\left(K_{2}\right), \mathrm{m} \leftrightarrow \mathrm{m}^{\prime}$, and $\mathrm{M} \leftrightarrow \mathrm{M}^{\prime}$ (see Figure 4, bottom) and activation barriers for isomerizations and dissociation of inner sphere water (semiquantitative).

energies across the entire lanthanide series, but the $\mathbf{M}^{\prime}$ isomer is too energetic for a lanthanide DOTA complex.

The activation barriers are known for the $\mathrm{M} \rightarrow \mathrm{m}$ transformation $\left(\Delta G_{306}{ }^{\ddagger} \cong 63 \mathrm{~kJ} \mathrm{~mol}^{-1}\right)$ from the line broadening experiments on $\left[\mathrm{Eu}(\mathrm{DOTA})\left(\mathrm{H}_{2} \mathrm{O}\right)\right]^{-}$and for the dissociation of the inner sphere water $\left(\Delta G_{306}{ }^{\ddagger} \cong 35 \mathrm{~kJ} \mathrm{~mol}^{-1}\right)$ from ${ }^{17} \mathrm{O}$ NMR. ${ }^{16 a}$ For the $\mathrm{M}^{\prime} \rightarrow \mathrm{m}^{\prime}$ isomerization the activation energy for the $\mathrm{M} \rightarrow \mathrm{m}$ reaction was corrected for the greater energy difference of the reactants so that the average activation energy in both directions stays the same. The same procedure leads to the height of the barrier for the $\mathrm{M} \rightarrow \mathrm{M}^{\prime}$ dissociation. The resulting semiquantitative graph (Figure 6) explains the result of the variable-pressure experiment on $\left[\mathrm{Eu}(\text { DOTA })\left(\mathrm{H}_{2} \mathrm{O}\right)\right]^{-}$: the $\mathrm{M} \rightarrow \mathrm{m}$ isomerization cannot pass through the $\mathrm{M}^{\prime}$ intermediate because the activation barrier for the conformational rearrangement $\mathbf{M}^{\prime} \rightarrow \mathrm{m}^{\prime}$ is too high. Even the $\mathrm{M} \rightarrow \mathrm{m}^{\prime}$ reaction will pass through the $\mathrm{m}$ and not the $\mathrm{M}^{\prime}$ isomer. The high barrier for the conformational rearrangement $M^{\prime} \rightarrow m^{\prime}$ excludes the $\mathbf{M}^{\prime}$ isomer as an intermediate for all isomerization reactions on the lanthanide complexes.

The presence of a variety of salts has an important effect upon the isomer distribution. Those containing anions like $\mathrm{F}^{-}$, which can bind into the first coordination sphere of the lanthanide, show a remarkable specificity in such binding. $\mathrm{F}^{-}$ binds to the lanthanide by replacing the inner sphere water, more strongly for the more open structure m of Eu(DOTA) ${ }^{-}$than to the tighter structure $\mathrm{M}$ of $\mathrm{Yb}(\mathrm{DOTA})^{-}$. The replacement of $\mathrm{H}_{2} \mathrm{O}$ by $\mathrm{F}^{-}$has no effect on the ligand dynamics of the $[\mathrm{Eu}(\mathrm{DOTA}) \mathrm{F}]^{2-}$ derivative, but the exchange rates between the aquo and fluoro $\mathrm{Ln}$ (DOTA) ${ }^{-}$complexes increase from $\mathrm{Eu}^{3+}$ to $\mathrm{Yb}^{3+}$, in agreement with the decreased stability of the fluoro derivative for the smaller cation, with a more crowded ninth coordination site.
The salts containing an anion that does not coordinate the $\mathrm{Ln}$ (III) directly, such as $\mathrm{Cl}^{-}, \mathrm{Br}^{-}, \mathrm{I}^{-}$, or $\mathrm{ClO}_{4}{ }^{-}$, shift the isomer equilibrium without forming new, stable chemical species with proton NMR signals in slow exchange with those already present, in opposition to $\mathrm{F}^{-}$. The isomer equilibrium is shifted in favor of the reverse antiprismatic conformation in isomers $\mathrm{m}$ or $\mathrm{m}^{\prime}$, relative to the prismatic in isomer $\mathrm{M}$. This shift in equilibrium, which is entropy driven, does not result from the effect of low water activity on stabilizing species without inner sphere water, as shown by UV-vis spectra of Eu(DOTA)- in the presence of high perchlorate concentrations. It is attributed to preferential stabilization of the reverse antiprismatic ligand conformation due to weak outer sphere binding of both cations and anions and to decreased availability of solvent water molecules to hydrate the two isomeric forms. Thus, weak outer sphere interactions are energetic enough to influence the ligand conformational equilibrum in such rigid chelates as the Ln(DOTA $)^{-}$complexes.

Acknowledgment. A.E.M. and D.P. thank Nycomed, Inc., the Swiss National Science Foundation (Grant No. 39483.93), and the Swiss OFES for their financial support. C.F.G.C.G. and M.P.M.M. thank JNICT, Portugal (Grants PBIC/S/SAU/ 1623/92 and Praxis XXI 2/2.2/SAU/1194/95) for financial support and Program CIENCIA for purchase of the Varian U500 NMR spectrometer. S.A., M.B., and M.F. thank Bracco, SPA, and the Italian CNR for their financial support and Alessandro Barge for synthetic help and NMR measurements. This research was carried out in the framework of the EC COST D1 program "Synthesis and Physicochemical Studies of Lanthanide and Transition Metal Chelates of relevance to Magnetic Resonance Imaging".

Supporting Information Available: Comparison of values of equilibrium constants for the isomer equilibrium reactions of the Ln(DOTA $)^{-}$complexes at room pressure $K_{0}$ and temperature $T$ obtained from the variable-temperature study and the variable-pressure study (Table S1), pressure dependence of the $R T \ln \left(K_{i p} / K_{i 0}\right)$ values for the isomer equilibria $\mathrm{m} \leftrightarrow \mathrm{M}(\mathrm{Ln}=\mathrm{Nd}, \mathrm{Eu})$ and $\mathrm{m} \leftrightarrow \mathrm{m}^{\prime}+\mathrm{H}_{2} \mathrm{O}(\mathrm{Ln}=$ $\mathrm{Yb}, \mathrm{Lu})$, respectively, for the $\left[\mathrm{Ln}(\mathrm{DOTA})\left(\mathrm{H}_{2} \mathrm{O}\right)_{x}\right]^{-}$complexes in aqueous solution ( $\mathrm{pH} 7.0,0.15 \mathrm{M}, 298 \mathrm{~K}$ ) (Figure S1), temperature dependence of the isomer equilibrium constants for $\left[\mathrm{Eu}(\mathrm{DOTA})\left(\mathrm{H}_{2} \mathrm{O}\right)_{x}\right]^{-}$ (0.041 M, pH 7.0 in $\mathrm{D}_{2} \mathrm{O}, 2 \mathrm{M} \mathrm{NaClO}_{4}$, and $2 \mathrm{M} \mathrm{NaCl}$ ) (Figure S2), $90 \mathrm{MHz}$ proton NMR spectra of $0.1 \mathrm{M}\left[\mathrm{Eu}(\text { DOTA })\left(\mathrm{H}_{2} \mathrm{O}\right)_{x}\right]^{-}(271 \mathrm{~K}$, $\mathrm{pH} 7.0$, in $\mathrm{D}_{2} \mathrm{O}$ in the absence and in the presence of $0.76 \mathrm{M} \mathrm{NaF}$ ) (Figure S3), 2D-EXSY $400 \mathrm{MHz}$ proton NMR spectrum of $0.1 \mathrm{M}$ $\left[\mathrm{Eu}(\mathrm{DOTA})\left(\mathrm{H}_{2} \mathrm{O}\right)_{x}\right]^{-}\left(271 \mathrm{~K}, \mathrm{pH} 7.0\right.$, in $\mathrm{D}_{2} \mathrm{O}$, in the presence of 0.76 $\mathrm{M} \mathrm{NaF}$ (mixing time $40 \mathrm{~ms}$ )) (Figure S4) (5 pages). Ordering information is given on any current masthead page.

IC9613640 